\title{
Elastic-Brittle-Plastic Behaviour of Shale Reservoirs and Its Implications on Fracture Permeability Variation: An Analytical Approach
}

\author{
Mohsen S. Masoudian ${ }^{1}\left[\right.$ - Mir Amid Hashemi ${ }^{1} \cdot$ Ali Tasalloti $^{1} \cdot$ Alec M. Marshall $^{1}$
}

Received: 19 July 2017 / Accepted: 22 December 2017 / Published online: 19 January 2018

(c) The Author(s) 2018. This article is an open access publication

\begin{abstract}
Shale gas has recently gained significant attention as one of the most important unconventional gas resources. Shales are fine-grained rocks formed from the compaction of silt- and clay-sized particles and are characterised by their fissured texture and very low permeability. Gas exists in an adsorbed state on the surface of the organic content of the rock and is freely available within the primary and secondary porosity. Geomechanical studies have indicated that, depending on the clay content of the rock, shales can exhibit a brittle failure mechanism. Brittle failure leads to the reduced strength of the plastic zone around a wellbore, which can potentially result in wellbore instability problems. Desorption of gas during production can cause shrinkage of the organic content of the rock. This becomes more important when considering the use of shales for $\mathrm{CO}_{2}$ sequestration purposes, where $\mathrm{CO}_{2}$ adsorption-induced swelling can play an important role. These phenomena lead to changes in the stress state within the rock mass, which then influence the permeability of the reservoir. Thus, rigorous simulation of material failure within coupled hydro-mechanical analyses is needed to achieve a more systematic and accurate representation of the wellbore. Despite numerous modelling efforts related to permeability, an adequate representation of the geomechanical behaviour of shale and its impact on permeability and gas production has not been achieved. In order to achieve this aim, novel coupled poro-elastoplastic analytical solutions are developed in this paper which take into account the sorption-induced swelling and the brittle failure mechanism. These models employ linear elasticity and a Mohr-Coulomb failure criterion in a plane-strain condition with boundary conditions corresponding to both open-hole and cased-hole completions. The post-failure brittle behaviour of the rock is defined using residual strength parameters and a non-associated flow rule. Swelling and shrinkage are considered to be elastic and are defined using a Langmuir-like curve, which is directly related to the reservoir pressure. The models are used to evaluate the stress distribution and the induced change in permeability within a reservoir. Results show that development of a plastic zone near the wellbore can significantly impact fracture permeability and gas production. The capabilities and limitations of the models are discussed and potential future developments related to modelling of permeability in brittle shales under elastoplastic deformations are identified.
\end{abstract}

Keywords Coupled geomechanics $\cdot$ Fractured reservoir $\cdot$ Shale gas $\cdot$ Permeability modelling $\cdot$ Poro-elasto-plasticity · Analytical solution

\section{List of symbols}

Applied Mechanics

$\sigma_{r r}, \sigma_{\theta \theta}, \sigma_{z z}$ Stress components in cylindrical coordinates

$\sigma_{\mathrm{h}} \quad$ Mean horizontal stress (i.e. average of $\left.\sigma_{r r}, \sigma_{\theta \theta}\right)$

Mohsen S. Masoudian

mohsen.masoudian@nottingham.ac.uk

1 Nottingham Centre for Geomechanics, University of Nottingham, University Park, Nottingham NG7 2RD, UK $\sigma_{0} \quad$ In situ horizontal stress under initial reservoir conditions

$\Delta \sigma_{\mathrm{h}}^{\prime} \quad$ Change in mean horizontal stress from the initial in situ conditions

$\varepsilon_{r r}, \varepsilon_{\theta \theta}, \varepsilon_{z z} \quad$ Strain components in cylindrical coordinates

$\varepsilon^{\mathrm{e}, \mathrm{m}} \quad$ The elastic part of mechanically induced strain

$\varepsilon_{v}^{\mathrm{e}, \mathrm{s}} \quad$ The sorption-induced volumetric strain (elastic only)

$\varepsilon^{\mathrm{p}} \quad$ The plastic part of strain

$\varepsilon_{v, 0}^{\mathrm{e}, \mathrm{s}} \quad$ The in situ swelling strain under initial reservoir conditions 


\begin{tabular}{|c|c|c|}
\hline$\alpha$ & Biot's coefficient & ZDCS \\
\hline$E$ & Elastic modulus & \\
\hline$v$ & Poisson's ratio & \\
\hline$c, \phi$ & Cohesion and friction angle, respectively & ZDZD \\
\hline$c_{\mathrm{r}}, \phi_{\mathrm{r}}$ & $\begin{array}{l}\text { Post-failure cohesion and friction angle, } \\
\text { respectively }\end{array}$ & $f(r)$ \\
\hline$\gamma, Y$ & $\begin{array}{l}\text { Strength parameters in Mohr-Coulomb } \\
\text { failure criterion defined using cohesion and } \\
\text { friction angle }\end{array}$ & $F_{\mathrm{p}}(r)$ \\
\hline$\gamma_{\mathrm{r}}, Y_{\mathrm{r}}$ & $\begin{array}{l}\text { Post-failure strength parameters in Mohr- } \\
\text { Coulomb failure criterion defined using } \\
\text { post-failure cohesion and friction angle }\end{array}$ & $F_{\varepsilon}(r)$ \\
\hline$\psi$ & Dilation angle & $F(r)$ \\
\hline$\beta$ & A function of dilation angle & \\
\hline$u_{\mathrm{ep}}$ & $\begin{array}{l}\text { Radial displacement at the elastic-plastic } \\
\text { interface }\end{array}$ & \\
\hline
\end{tabular}

\section{Geometry}

$r, \theta, z$

$R_{0}$

$R_{\mathrm{w}}$

$R_{\text {ep }}$

Directions in cylindrical coordinates (the origin is the centre of the wellbore)

Radius of the disc-shaped reservoir

Radius of the wellbore

Radius of plastic zone developed around the wellbore

\section{Flow and Sorption Parameters}

$P \quad$ Pore pressure (fracture porosity)

$p_{0} \quad$ Uniform pore pressure in the reservoir under initial condition

$p_{\mathrm{w}} \quad$ Wellbore pressure (constant during gas production)

$Q \quad$ Coefficient of pore pressure reduction due to gas production with the steady-state logarithmic pressure distribution

$Q_{\mathrm{D}} \quad$ Dimensionless production rate

$k \quad$ Permeability of the reservoir

$k_{0} \quad$ Permeability of the reservoir under initial conditions

$c_{\mathrm{f}} \quad$ Fracture compressibility

$V^{\mathrm{s}} \quad$ Volume of adsorbed gas

$V_{\mathrm{L}}^{\mathrm{s}}, b_{\mathrm{L}} \quad$ Maximum monolayer sorption capacity and Langmuir isotherm constant, respectively

$\varepsilon_{\mathrm{L}}^{\mathrm{s}} \quad$ Maximum swelling strain

\section{Solution-Dependent Definitions}

$A, B, K \quad$ Constants defined in stress and displacement solutions

$C_{1}, C_{2}, C_{3}$ $\mathrm{CSCS}$

CSZD
Integration constants for stress solutions

Acronym for constant stress condition on both boundaries

Acronym for constant stress condition on wellbore boundary and zero displacement condition on outer boundary
Acronym for zero displacement condition on wellbore boundary and constant stress condition on outer boundary

Acronym for zero displacement condition on both boundaries

A special function defined from distributions of pore pressure and sorption-induced strain Integral of pore pressure function over the domain of the reservoir Integral of sorption-induced strain function over the domain of the reservoir A special function defined from $F_{\mathrm{p}}(r)$ and $F_{\varepsilon}(r)$

\section{Introduction}

Unconventional gas reservoirs are increasingly being considered to provide a relatively clean energy source to meet burgeoning global demands. Unconventional gas resources, such as shale, represent around $40 \%$ of the remaining resource of technically recoverable natural gas; hence, they play an important role in the future global energy market (McGlade et al. 2013). In addition, unconventional gas reservoirs are being considered as a host rock for $\mathrm{CO}_{2}$ geosequestration, which may also provide an enhanced gas recovery (EGR) technique. Shales are fine-grained rocks formed from the compaction of silt- and clay-sized particles and are characterised by their fissured texture and very low permeability $\left(10^{-18}-10^{-23} \mathrm{~m}^{2}\right.$ ) (Alexander et al. 2011). Gas shales can be considered as a dual porosity rock consisting of fractures and matrix blocks (Fig. 1), with a porosity of up to $15 \%$ (Wang and Reed 2009). Fracture sets can be subvertical or parallel to bedding, may be filled with mineral gauges, have openings ranging in scale from micrometres to centimetres, and spacing ranging in scale from a few centimetres to several metres (Gale et al. 2014). The matrix usually contains an organic content of $2-10 \%$, while those with higher organic contents are usually considered too immature for production development (Alexander et al. 2011). The matrix contains porosity in the scale of $\mu \mathrm{m}$ to $\mathrm{nm}$ in size within different organic (fibrous) and nonorganic (clastic) structures (Mehmani et al. 2013). Natural gas can be free within both the fracture (primary porosity) and clastic structure of the matrix (secondary porosity), or in an adsorbed state on the surface of the porous structure of organic content. The adsorption of gas in organic geomaterials can be described using an isotherm, among which Langmuir's is most widely used (Gensterblum et al. 2015). For example, the gas content of five reservoirs in the USA, with in situ pressures between 2 and $28 \mathrm{MPa}\left(600-8500 \mathrm{~m}\right.$ deep), ranged from 1 to $10 \mathrm{~m}^{3} /$ 
Fig. 1 a Fractures in shale core samples (Gale et al. 2014), b a subvertical calcite-cemented fracture (Soeder 1988), c simplified dual porosity concept for shale (a)

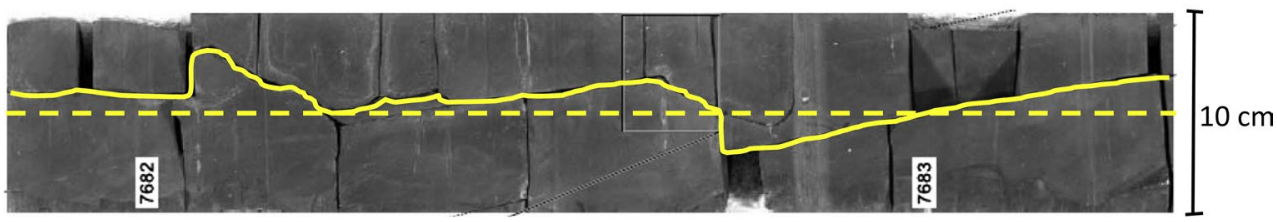

(b)

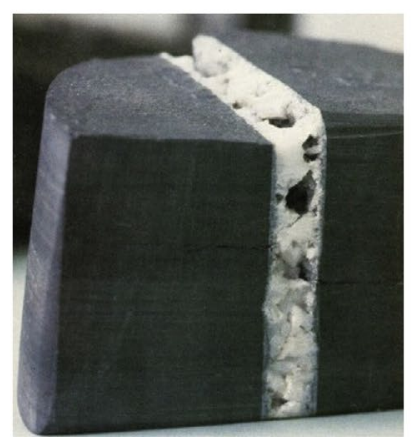

(c)

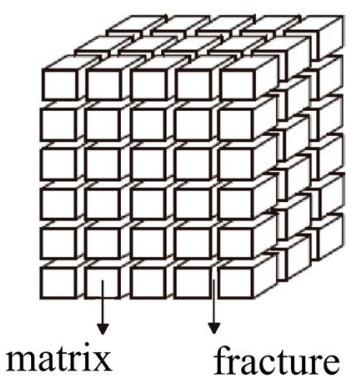

ton, of which $20-85 \%$ was adsorbed in the organic content (Curtis 2002; Hill and Nelson 2000).

Due to the multi-scale and multiple physical phenomena associated with shale gas production, the mechanism of gas flow is a combination of viscous (Darcy and non-Darcy) flow (Huang et al. 2016), and gas-slippage (Klinkenberg) effect (Mehmani et al. 2013), as well as continuum (Fickian), free-molecule (Knudsen), and surface (Yuan et al. 2014) diffusions. On the other hand, the gas sorption (adsorption and/ or desorption) also plays an important role in the gas transport mechanism in shale reservoirs, given that the amount of adsorbed gas in the organic content is comparable with the free gas. Despite the large number of studies on primary and $\mathrm{CO}_{2}$-EGR, many aspects of shale gas development are still not well understood, mainly due to the complex interactions of fluid flow with different thermal, chemical, and mechanical phenomena. For instance, withdrawal of water and gas from a subsurface formation results in significant reservoir pressure alteration, which in turn leads to a redistribution of stress and strain within the shale formation. Gas and water sorption-induced swelling/shrinkage (Lyu et al. 2015; Yuan et al. 2014), thermal phenomena (e.g. during thermal stimulation (Carroll et al. 2011)), and chemical reactions of water or $\mathrm{CO}_{2}$ (in case of $\mathrm{CO}_{2}$-EGR) with shale (Carroll et al. 2011) can additionally impact the stress-strain relations. Redistribution of stress and strain within any reservoir can subsequently lead to other changes, such as reservoir permeability alterations, subsidence/uplift of the ground surface, fault-reactivation mechanisms, and crack development in the caprock (Masoudian et al. 2016a).

Prediction of permeability has received considerable attention due to its significant effect on gas production from reservoirs. Numerous studies have related the permeability of gas shales to changes in the stress level (e.g. AmannHildenbrand et al. 2012; Chen et al. 2015a; Cho et al. 2013; Li et al. 2016; Spencer 1989; Zhou et al. 2016). However, these studies have only considered the elastic behaviour of the rock. Plastic deformations within the reservoir rock can have significant implications for production, injectivity, and stability of the wellbore. Studies have demonstrated the significance of both elastic and plastic deformations on wellbore producibility and/or injectivity as well as permeability prediction in other types of reservoirs (e.g. Cui et al. 2007; Han and Dusseault 2003; Masoudian et al. 2016b). In addition, the stability of wellbores is an important issue in any oil and gas production project. Therefore, improved models are needed to properly estimate the deformation and stress distributions around the wellbore. Experimental studies have also revealed the brittle mechanism of failure in shale (e.g. Amann et al. 2011; Hull et al. 2015; Sone and Zoback 2013), which implies the need for improved models that consider this failure mechanism. The effect of gas and/ or water sorption-induced swelling should also be taken into account when developing permeability models.

The most common geomechanical assumption when predicting permeability in gas reservoirs is of one-dimensional elastic deformation (vertical deformation). However, this assumption cannot provide an accurate estimation, especially near the wellbore where plastic deformations may occur. On the other hand, using fully numerical hydro-mechanical models leads to substantially more expensive computations. This is especially important in shale gas reservoirs where complex multiple porosity reservoir models are utilised. This study aims to extend previous work (Masoudian and Hashemi 2016) by further developing brittle elastoplastic models for reservoirs coupled with sorption-induced 
swelling/shrinkage effects. In this paper, models are developed with boundary conditions that simulate different well completions and geological settings (e.g. open-hole and cased-hole completions). The models are then used to estimate the stress distribution within the reservoir, with which the changes in fracture permeability within both elastic and plastic zones are predicted. This is an important aspect of the work that has been largely neglected in other studies, mainly due to lack of computational resources for field scale fully coupled hydro-elastoplastic simulations. This work aims to highlight the role of plastic deformations in the prediction of permeability and its impact on gas production.

\section{Theoretical Framework and Governing Equations}

The reservoir is assumed to be a disc-shaped homogenous isotropic continuum. A vertical wellbore is assumed to be drilled at the centre of the disc, through which natural gas can be produced. It should be noted that these simplifying assumptions are employed in order to develop a fully analytical framework in this paper. Clearly, these assumptions cannot fully represent the heterogeneous nature of shale; however, they do not prevent evaluation of the effect of elastoplastic deformations on stress and permeability distributions within reservoirs, which is the focus of this paper. Here, a simplified multi-continuum approach is adopted, where the rock is considered as a continuum at the field scale, while the fractured nature of the rock is captured by the effect of stress on fracture porosity. Figure 2a illustrates the geometry of the model and the multicontinuum approach adopted in this study. Figure $2 b$ depicts the stress-strain relations within the brittle elastoplastic framework used in this paper. Note that the mechanical behaviour of brittle rock is idealised with a sudden drop of strength from peak to residual value. Similar to perfectly plastic behaviour, there is no further change in stress beyond the yield point as plastic strains continue to accumulate. The governing equations employed in this paper are explained below.

Starting with the classical approach in plasticity, strains can be decomposed into elastic $\left(\varepsilon^{\mathrm{e}}\right)$ and plastic $\left(\varepsilon^{\mathrm{p}}\right)$ components, where the elastic strain can be further divided into elastic mechanical strain, $\left(\varepsilon^{\mathrm{e}, \mathrm{m}}\right)$, and elastic swelling (or shrinkage) strain, $\left(\varepsilon^{\mathrm{e}, \mathrm{s}}\right)$. Note that adsorption induces swelling while desorption leads to shrinkage of the matrix blocks. Assuming axial symmetry of the problem and considering a cylindrical system of coordinates $(r, \theta, z$ for radial, tangential and vertical directions, respectively), the strain compatibility equation is

$\frac{\partial \varepsilon_{\theta \theta}}{\partial r}=\frac{\varepsilon_{r r}-\varepsilon_{\theta \theta}}{r}$

where $r$ is the radial distance from the centre of a discshaped reservoir, and subscripts $r r$ and $\theta \theta$ represent the radial and tangential coordinates, respectively. In the light of
Fig. 2 Schematics of a the geometry of the model, the multi-continuum approach, and the swelling/shrinkage effect on matrix size, and $\mathbf{b}$ the stress and strain relationships in the adopted elastoplastic framework

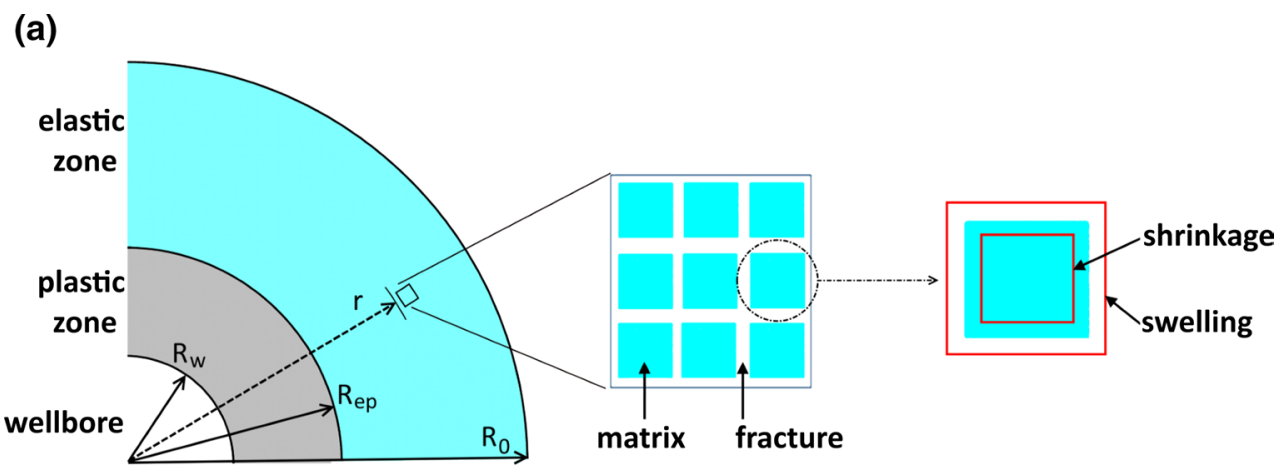

(b)

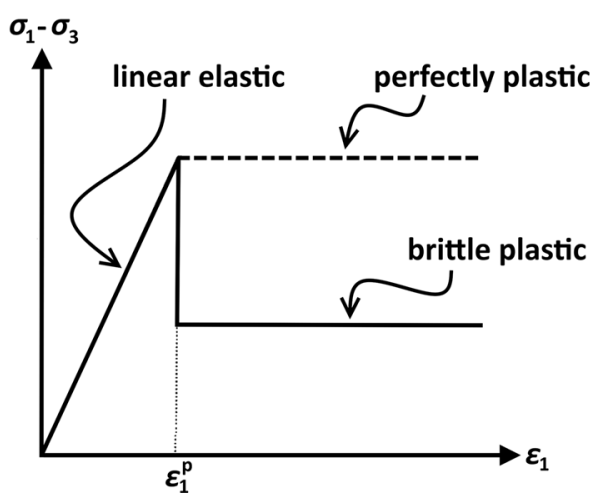


Biot's definition of effective stress $\left(\sigma^{\prime}=\sigma-\alpha P\right)$, the equation of equilibrium can be written as

$\frac{\partial \sigma_{r r}^{\prime}}{\partial r}=\frac{\sigma_{\theta \theta}^{\prime}-\sigma_{r r}^{\prime}}{r}-\alpha \frac{\partial P}{\partial r}$

where $P$ is pore pressure, $\alpha$ is Biot's coefficient, and $\sigma^{\prime}$ is effective stress. Assuming that swelling strain is analogous to thermal strain, the elastic stress-strain constitutive relations for an isotropic rock can be written as

$$
\begin{aligned}
& \varepsilon_{r r}=\frac{1}{E}\left[\sigma_{r r}-v\left(\sigma_{\theta \theta}+\sigma_{z z}\right)-(1-2 v) \alpha P\right]+\frac{\varepsilon_{v}^{\mathrm{e}, \mathrm{s}}}{3} \\
& \varepsilon_{\theta \theta}=\frac{1}{E}\left[\sigma_{\theta \theta}-v\left(\sigma_{z z}+\sigma_{r r}\right)-(1-2 v) \alpha P\right]+\frac{\varepsilon_{v}^{\mathrm{e}, \mathrm{s}}}{3} \\
& \varepsilon_{z z}=\frac{1}{E}\left[\sigma_{z z}-v\left(\sigma_{r r}+\sigma_{\theta \theta}\right)-(1-2 v) \alpha P\right]+\frac{\varepsilon_{v}^{\mathrm{e}, \mathrm{s}}}{3}
\end{aligned}
$$

where $E, v$ and $\varepsilon_{v}^{\mathrm{e}, \mathrm{s}}$ are the elastic modulus, Poisson's ratio, and volumetric swelling strain, respectively. The linear Mohr-Coulomb yield criterion can be written as

$\sigma_{\theta \theta}^{\prime}=\gamma \sigma_{r r}^{\prime}+Y$

where $\sigma_{\theta \theta}^{\prime}$ and $\sigma_{r r}^{\prime}$ are the tangential and radial effective stresses, respectively. The parameters $\gamma$ and $Y$ are defined using cohesion, $c$, and friction angle, $\phi$, of the rock as

$\gamma=\frac{1+\sin \phi}{1-\sin \phi}$

$Y=\frac{2 c \cos \phi}{1-\sin \phi}$

Note that by substituting the residual cohesion, $c_{\mathrm{r}}$, and friction angle, $\phi_{\mathrm{r}}$, into these equations, the residual parameters $\gamma_{\mathrm{r}}$ and $Y_{\mathrm{r}}$ can be defined for failed brittle rock. Considering a non-associated flow rule, the plastic components of radial and tangential strains are related as (Park and Kim 2006)

$$
\begin{aligned}
\varepsilon_{r r}^{\mathrm{p}}+\beta \varepsilon_{\theta \theta}^{\mathrm{p}} & =0 \\
\frac{\partial u}{\partial r}+\beta \frac{u}{r} & =\varepsilon_{r r}^{\mathrm{e}}+\beta \varepsilon_{\theta \theta}^{\mathrm{e}}
\end{aligned}
$$

where $u$ is the radial displacement, and $\beta$ is a function of dilation angle, $\psi$, as

$\beta=\frac{1+\sin \psi}{1-\sin \psi}$

There are a large number of studies that have investigated modelling approaches for flow of gas (methane or carbon dioxide) in shale reservoirs, where the complex multi-porous nature of shale is carefully considered and different mass transport mechanisms (i.e. viscous and diffusive) are taken into account. However, for the comparative analyses in this paper, a simplified pressure solution is sufficient. To arrive at a simplified pressure solution, the reservoir is initially assumed to be under a uniform pore pressure regime. Gas production from the wellbore with a fixed pressure $\left(p_{\mathrm{w}}\right)$ leads to the development of a non-uniform pore pressure distribution, with pressure remaining equal to the initial pressure at the outer boundary only. Thus, a steady-state solution of radial flow can be found in the following logarithmic form (Cui et al. 2007)

$P=p_{0}+Q \ln \left(\frac{r}{R_{0}}\right)$

where $p_{0}$ and $R_{0}$ are the initial reservoir pressure and radius of the disc-shaped reservoir, respectively. The term $Q$ is defined as

$Q=\frac{p_{\mathrm{w}}-p_{0}}{\ln \left(R_{\mathrm{w}} / R_{0}\right)}$

where $R_{\mathrm{w}}$ and $p_{\mathrm{w}}$ are the radius and pressure of the wellbore, respectively.

The volume of adsorbed gas, $V^{\mathrm{s}}$, can be estimated using Langmuir's isotherm as a function of pressure $(P)$

$V^{\mathrm{s}}=\frac{V_{\mathrm{L}}^{\mathrm{s}} b_{\mathrm{L}} P}{1+b_{\mathrm{L}} P}$

where $V_{\mathrm{L}}^{\mathrm{s}}$ is the maximum sorption capacity and $b_{\mathrm{L}}$ is the Langmuir isotherm constant. Initially, the matrix of the reservoir rock contains a specified amount of adsorbed gas at the initial pressure $\left(p_{0}\right)$ which changes as the reservoir pressure decreases due to production. As a result, the volumetric swelling strain changes from the initial state of $\varepsilon_{v, 0}^{\mathrm{e}, \mathrm{s}}$ to $\varepsilon_{v}^{\mathrm{e}, \mathrm{s}}$ and is considered to have a linear relationship with adsorbed gas volume, which gives

$\varepsilon_{v}^{\mathrm{e}, \mathrm{s}}=\frac{\varepsilon_{\mathrm{L}}^{\mathrm{s}} b_{\mathrm{L}} P}{1+b_{\mathrm{L}} P}$

where $\varepsilon_{\mathrm{L}}^{\mathrm{s}}$ is the maximum swelling strain that can only take place when the gas within the matrix is equal to the sorption capacity. Note that $\varepsilon_{v, 0}^{\mathrm{e}, \mathrm{s}}$ is used to account for the in situ equilibrium state of the reservoir and can be estimated directly using the equation above, replacing the pressure with $p_{0}$.

There are a number of fracture porosity/permeability models developed for reservoirs where adsorption-induced swelling or shrinkage is associated with gas injection or production (e.g. Gensterblum et al. 2015; Pan and Connell 2012). However, these models adopt two main approaches for porosity/permeability modelling: dependency on stress or strain. Both of these approaches are closely related and may lead to very similar results under certain conditions (Palmer 2009), as they both consider a cubic law to link permeability to fracture porosity (consistent with a Kozeny-Carman type relationship). In this paper, results are obtained with 
the most widely used approach where the permeability is related to the change in horizontal effective stress using an exponential equation as (Shi and Durucan 2005)

$k / k_{0}=\exp \left(-3 c_{\mathrm{f}} \Delta \sigma_{\mathrm{h}}^{\prime}\right)$

where $k$ is permeability, the subscript 0 denotes an initial value, $c_{\mathrm{f}}$ is fracture compressibility, and $\Delta \sigma_{\mathrm{h}}^{\prime}$ is the change in horizontal effective stress, which can be defined as the mean of the change in the radial and tangential components of effective stress. As illustrated in Fig. 2a, any element of rock (i.e. at a specific value of $r$ ) can be conceptualised as a hybrid of fractures and matrix blocks and any change in stress state (due to pore pressure reduction and swelling/ shrinkage effects) results in a change in the aperture size of the fractures within that element. Equation 12 therefore provides an efficient method for relating the response of fractures and their permeability at fracture scale to the changes in effective stress at field scale. The use of mean horizontal effective stress implies a matchstick matrix model, which is consistent with the plane-strain assumption. Closed-form solutions of permeability and porosity can then be obtained by substituting the stress and strain equations for different loading and boundary conditions into the above equations. It should be noted, however, that experimental results have shown that the relationship between post-failure permeability and the stress-strain state can be much more complex than what these models offer (e.g. Carey et al. 2015). However, due to the lack of dedicated post-failure models, this widely used simplified approach was adopted in this paper. Limitations of the model are discussed later in the paper.

\section{Analytical Solutions for Elastic-Brittle- Plastic Rock}

Following the approach employed by Masoudian and Hashemi (2016), analytical solutions for stress and strain around a wellbore can be found by assuming two distinct concentric zones; a plastic zone near the wellbore and an elastic zone towards the outer boundary. The derivation and development of these solutions are partially presented in "Appendix 1". The interface of elastic and plastic zones is at a radial distance of $R_{\mathrm{ep}}$ from the wellbore centre. The general solution within the elastic zone $\left(r>R_{\mathrm{ep}}\right)$ can be written as

$$
\begin{aligned}
\left.\sigma_{r r}\right|_{r>R_{\text {ep }}}= & C_{1}+\frac{F(r)-C_{2}}{r^{2}} \\
\left.\sigma_{\theta \theta}\right|_{r>R_{\text {ep }}}= & C_{1}-\frac{F(r)-C_{2}}{r^{2}}+f(r) \\
\left.u\right|_{r>R_{\text {ep }}}= & \frac{(1+v)}{E}\left[(1-2 v) r\left(C_{1}-\sigma_{0}+\alpha p_{0}\right)\right. \\
& \left.+\frac{C_{2}}{r}-\frac{F(r)}{r}+\frac{E}{3} r \varepsilon_{v, 0}^{\mathrm{e}, \mathrm{s}}\right]
\end{aligned}
$$

where $C_{1}$ and $C_{2}$ are the integration constants that can be determined from the boundary conditions, and

$$
\begin{aligned}
f(r) & =\frac{(1-2 v)}{(1-v)} \alpha P+\frac{E}{3(1-v)} \varepsilon_{v}^{\mathrm{es} s} \\
F(r) & =\frac{(1-2 v)}{(1-v)} F_{\mathrm{p}}(r)+\frac{E}{3(1-v)} F_{\varepsilon}(r) \\
F_{\mathrm{p}}(r) & =\int_{0}^{r} \alpha P \rho \mathrm{d} \rho=-\frac{r^{2}}{4} \alpha Q+\frac{r^{2}}{2} \alpha P \\
F_{\varepsilon}(r) & =\int_{0}^{r} \varepsilon_{v}^{\varepsilon, s} \rho \mathrm{d} \rho=\varepsilon_{\mathrm{L}}^{\mathrm{s}}\left[\frac{r^{2}}{2}-\frac{R_{0}^{2}}{b_{\mathrm{L}} Q} \exp \left(-2 \frac{1+b_{\mathrm{L}} p_{0}}{b_{\mathrm{L}} Q}\right) E i\left(2 \times \frac{1+b_{\mathrm{L}} P}{b_{\mathrm{L}} Q}\right)\right]
\end{aligned}
$$

where $\operatorname{Ei}(x)$ is the exponential integral function.

The stress and strain relations within the plastic zone near the wellbore are governed by a Mohr-Coulomb failure envelope and a non-associated flow rule. Note that the brittle failure mechanism is implemented using residual strength parameters (i.e. cohesion and friction angle); perfectly plastic behaviour could be modelled by using peak strength values. The general solution in the plastic zone can then be written as

$$
\begin{aligned}
\left.\sigma_{r r}^{\prime}\right|_{r<R_{\mathrm{ep}}}= & C_{3} r^{\gamma_{\mathrm{r}}-1}-K \\
\left.\sigma_{\theta \theta}^{\prime}\right|_{r<R_{\mathrm{ep}}}= & Y_{\mathrm{r}}+\gamma_{\mathrm{r}}\left(C_{3} r^{\gamma_{\mathrm{r}}-1}-K\right) \\
\left.u\right|_{r<R_{\mathrm{ep}}}= & \frac{(1+v)}{E} r^{-\beta}\left[\frac{E u_{\mathrm{ep}}}{1+v} R_{\mathrm{ep}}^{\beta}-C_{3} A \frac{R_{\mathrm{ep}}^{\beta+\gamma_{\mathrm{r}}}-r^{\beta+\gamma_{\mathrm{r}}}}{\beta+\gamma_{\mathrm{r}}}\right. \\
& \left.-\left(B Y_{\mathrm{r}}-A K\right) \frac{R_{\mathrm{ep}}^{\beta+1}-r^{\beta+1}}{\beta+1}+\frac{1+\beta}{3} E\left(F_{\varepsilon, \beta}\left(R_{\mathrm{ep}}\right)-F_{\varepsilon, \beta}(r)\right)\right]
\end{aligned}
$$

where

$$
\begin{aligned}
& A=1-\nu-v \gamma_{\mathrm{r}}+\beta\left(\gamma_{\mathrm{r}}-v-v \gamma_{\mathrm{r}}\right) \\
& B=\beta-\beta \nu-\nu \\
& K=\frac{Y_{\mathrm{r}}-\alpha Q}{\gamma_{\mathrm{r}}-1} \\
& F_{\varepsilon, \beta}(r)=\varepsilon_{\mathrm{L}}^{\mathrm{s}}\left[\frac{r^{1+\beta}}{1+\beta}-\frac{R_{0}^{1+\beta}}{b_{\mathrm{L}} Q} \exp \left(-(1+\beta) \frac{1+b_{\mathrm{L}} p_{0}}{b_{\mathrm{L}} Q}\right)\right. \\
&\left.\quad \times E i\left((1+\beta) \frac{1+b_{\mathrm{L}} P}{b_{\mathrm{L}} Q}\right)\right]
\end{aligned}
$$

where $Y_{\mathrm{r}}$ and $\gamma_{\mathrm{r}}$ are obtained with residual values of cohesion and friction angle in Eq. 5, and $u_{\text {ep }}$ is the displacement at the elastic-plastic interface, which can be found considering continuity of displacement at the interface, i.e. by replacing the value of $R_{\mathrm{ep}}$ in the elastic solution of displacement (Eq. 13) once the value $R_{\text {ep }}$ is found. To obtain $R_{\text {ep }}$, the integration constants $C_{1}, C_{2}$, and $C_{3}$ are found by substituting different sets of boundary conditions into the general solution, as presented in Table 1. Each set of boundary conditions describes a particular geological and well completion condition. The constant stress at the wellbore represents an uncased hole; hence, the total stress applied to the inner boundary is equal to the bottomhole pressure 
$\left(p_{\mathrm{w}}\right)$; i.e. zero effective stress on wellbore wall. On the other hand, zero displacement on the wellbore wall represents an ideally cased hole that does not allow the wellbore wall to converge. For the outer boundary, the constant stress represents an ideal scenario where the reservoir is completely separated from the adjacent formation. Zero displacement at the outer boundary represents a scenario where the reservoir is large enough to prevent deformation of the rock mass at the far-field. For example, if the reservoir was cut by lowangle faults at the outer boundary, the reservoir may be best simulated by applying a constant stress, whereas a zero horizontal displacement boundary would be more suitable if the reservoir was cut by steep faults and was in contact with mechanically strong geological strata. However, due to the geological complexity of reservoirs, actual boundary condition will fall somewhere between these two conditions; hence, different boundary conditions should be tested. The boundary condition acronyms consist of four letters, with the first pair describing the condition of the wellbore wall, and the second pair describing the condition of the outer boundary. As such, case CSCS represents constant stresses (CS) on both the wellbore wall and outer boundary, case ZDCS represents zero displacement (ZD) of the wellbore wall and constant stress on the outer boundary, case CSZD represents constant stress on the wellbore wall and zero displacement of the outer boundary, and case ZDZD represents zero displacement on both the wellbore wall and outer boundary.

The interface between elastic and plastic zones is found considering the continuity of radial stress at $r=R_{\text {ep }}$ and a trial-and-error scheme. To achieve this, an equality is constructed using the solution of radial stress within both elastic and plastic zones, and then its root for $R_{\mathrm{ep}}$ can be found. If this equality does not have a root in the $\left[R_{\mathrm{w}}, R_{0}\right]$ domain, it means that the rock mass does not include a plastic zone and hence a fully elastic solution is used by replacing $R_{\text {ep }}$ by $R_{\mathrm{w}}$ in Eq. 13 with the corresponding elastic integration constants presented in "Appendix 2". These formulations and the introduced methodology were implemented in a MATLAB code and used to obtain the results discussed in the following section.

Table 1 Integration constants for different sets of boundary conditions

Boundary conditions (acronym) Relationships

Constant stress at $R_{\mathrm{w}}$

Constant stress at $R_{0}$ (CSCS)

Zero displacement at $R_{\mathrm{w}}$ Constant stress at $R_{0}$ (ZDCS)

Constant stress at $R_{\mathrm{w}}$ Zero displacement at $R_{0}$ (CSZD)

Zero displacement at $R_{\mathrm{w}}$ Zero displacement at $R_{0}$ (ZDZD)

$$
\begin{aligned}
C_{1} & =\frac{R_{\mathrm{ep}}^{2}\left[Y-f\left(R_{\mathrm{ep}}\right)-(\gamma-1) \alpha P\left(R_{\mathrm{ep}}\right)\right]+(\gamma+1)\left[F\left(R_{\mathrm{ep}}\right)-F\left(R_{0}\right)+R_{0}^{2} \sigma_{0}\right]}{R_{0}^{2}(\gamma+1)-R_{\mathrm{ep}}^{2}(\gamma-1)} \\
C_{2} & =\left(C_{1}-\sigma_{0}\right) R_{0}^{2}+F\left(R_{0}\right) \\
C_{3} & =\frac{K}{R_{\mathrm{w}}^{\mathrm{r}-1}}
\end{aligned}
$$

$C_{1}=\frac{R_{\mathrm{ep}}^{2}\left[Y-f\left(R_{\mathrm{ep}}\right)-(\gamma-1) \alpha P\left(R_{\mathrm{ep}}\right)\right]+(\gamma+1)\left[F\left(R_{\mathrm{ep}}\right)-F\left(R_{0}\right)+R_{0}^{2} \sigma_{0}\right]}{R_{0}^{2}(\gamma+1)-R_{\mathrm{ep}}^{2}(\gamma-1)}$

$C_{2}=\left(C_{1}-\sigma_{0}\right) R_{0}^{2}+F\left(R_{0}\right)$

$C_{3}=\frac{\beta+\gamma_{\mathrm{r}}}{A\left(R_{\mathrm{ep}}^{\beta+\gamma_{\mathrm{r}}}-r^{\beta+\gamma_{\mathrm{r}}}\right)} \times\left\{\frac{E u_{\mathrm{ep}}}{1+\nu} R_{\mathrm{ep}}^{\beta}-\left(B Y_{\mathrm{r}}-A K\right) \frac{R_{\mathrm{ep}}^{\beta+1}-R_{\mathrm{w}}^{\beta+1}}{\beta+1}+\frac{1+\beta}{3} E\left(F_{\varepsilon, \beta}\left(R_{\mathrm{ep}}\right)-F_{\varepsilon, \beta}\left(R_{\mathrm{w}}\right)\right)\right\}$

$C_{1}=\frac{1}{R_{e p}^{2}(1-\gamma)-R_{0}^{2}(1+\gamma)(1-2 v)} \times\left\{R_{\mathrm{ep}}^{2}\left[Y-f\left(R_{\mathrm{ep}}\right)-(\gamma-1) \alpha P\left(R_{\mathrm{ep}}\right)\right]\right.$

$$
\left.+(\gamma+1)\left(F\left(R_{\mathrm{ep}}\right)-F\left(R_{0}\right)+R_{0}^{2}\left[\frac{E}{3} \varepsilon_{v, 0}^{\mathrm{e}, \mathrm{s}}-(1-2 v)\left(\sigma_{0}-\alpha p_{0}\right)\right]\right)\right\}
$$

$C_{2}=F\left(R_{0}\right)-R_{0}^{2}\left[(1-2 v)\left(C_{1}-\sigma_{0}+\alpha p_{0}\right)+\frac{E}{3} \varepsilon_{v, 0}^{\mathrm{e}, \mathrm{s}}\right]$

$C_{3}=\frac{K}{R_{\mathrm{w}}^{r-1}}$

$$
\begin{aligned}
& C_{1}=\frac{1}{R_{e p}^{2}(1-\gamma)-R_{0}^{2}(1+\gamma)(1-2 v)} \times\left\{R_{\mathrm{ep}}^{2}\left[Y-f\left(R_{\mathrm{ep}}\right)-(\gamma-1) \alpha P\left(R_{\mathrm{ep}}\right)\right]\right. \\
& \left.+(\gamma+1)\left(F\left(R_{\mathrm{ep}}\right)-F\left(R_{0}\right)+R_{0}^{2}\left[\frac{E}{3} \varepsilon_{v, 0}^{\mathrm{e}, \mathrm{s}}-(1-2 \nu)\left(\sigma_{0}-\alpha P\right)\right]\right)\right\} \\
& C_{2}=F\left(R_{0}\right)-R_{0}^{2}\left[(1-2 \nu)\left(C_{1}-\sigma_{0}+\alpha p_{0}\right)+\frac{E}{3} \varepsilon_{v, 0}^{\mathrm{e}, \mathrm{s}}\right] \\
& C_{3}=\frac{\beta+\gamma_{\mathrm{r}}}{A\left(R_{\mathrm{ep}}^{\beta+\gamma_{\mathrm{r}}}-r^{\beta+\gamma_{\mathrm{r}}}\right)} \times\left\{\frac{E u_{\mathrm{ep}}}{1+\nu} R_{\mathrm{ep}}^{\beta}-\left(B Y_{\mathrm{r}}-A K\right) \frac{R_{\mathrm{ep}}^{\beta+1}-R_{\mathrm{w}}^{\beta+1}}{\beta+1}+\frac{1+\beta}{3} E\left(F_{\varepsilon, \beta}\left(R_{\mathrm{ep}}\right)-F_{\varepsilon, \beta}\left(R_{\mathrm{w}}\right)\right)\right\}
\end{aligned}
$$




\section{Results and Discussion}

In order to examine the stress change and permeability evolution around a gas production well, a set of values were chosen for the model input parameters, as listed in Table 2. These values mainly represent gas shale reservoirs (suitable for hydraulic fracturing due to their brittleness) and were chosen to be within the reported ranges from the corresponding references. Studies have shown that hydro-mechanical properties of near-wellbore shales are influenced by the presence of natural and hydraulically generated fractures (Liang et al. 2014; Song et al. 2014), and the exposure of rock to drilling mud (Ma and Chen 2015). However, these effects are not considered in this paper. It should also be noted that the sorption and swelling parameters correspond to those of organic rich shales.

With production of gas from the reservoir, the pore pressure decreases following Eq. 8, and the uniform initial pore pressure is replaced by a radial distribution with maximum pressure at the outer boundary (initial reservoir pressure, $p_{0}$ ) and minimum value on the wellbore wall (wellbore pressure, $p_{\mathrm{w}}$ ). During production, the gas is desorbed from the matrix of the rock which leads to matrix shrinkage. The change in pore pressure combined with sorption-induced shrinkage leads to a redistribution of stress within the rock mass. The distributions of radial and tangential total stresses for all sets of boundary conditions are presented in Fig. 3. Note that the effective stresses can be evaluated by subtracting pore pressure from the total stresses (considering $\alpha=1$ ); this will be discussed later in the paper. It can be seen that in ZDCS and
ZDZD scenarios (representing cased-hole completions), the radial stress significantly increases near the wellbore (moving towards the wellbore from right to left in Fig. 3), since the rock is restricted on the wellbore wall. On the other hand, the tangential stress in these cases monotonically decreases as you approach the wellbore. This is because the support provided by the casing does not allow radial deformations and the release of radial stress within the rock mass. As a result, the change in radial and tangential effective stresses (which is due to the interaction between pore pressure in the fractures and shrinkage of the matrix of the rock) is not large enough to satisfy the yield criterion (due to large minimum principal stress levels) and the rock remains elastic, i.e. there is no plastic zone around the wellbore. It should also be noted that the case with constant stress at the outer boundary (ZDCS) exhibits higher stress levels compared to the case with a fixed outer boundary (ZDZD). This is because in ZDCS, the applied stress at the far-field compresses the rock mass towards the wellbore and results in a larger stress applied on the casing of the wellbore.

In the CSCS and CSZD cases (representing open-hole completions), as the wellbore is radially deformed, the radial stress decreases towards the wellbore pressure of $5 \mathrm{MPa}$ in the approach to the wellbore. The tangential stress in these cases, however, increases to some point and then suddenly decreases in the approach to the wellbore. This is because the circular opening allows some deformation of the rock towards the wellbore which is also enhanced by the production-induced reduction of pore pressure and the desorptioninduced shrinkage of the rock matrix. In these cases, the combination of stress levels satisfies the Mohr-Coulomb
Table 2 Input parameters for the base simulation case

\begin{tabular}{lllll}
\hline Parameter & Symbol & Value & Unit & References \\
\hline Young's modulus & $E$ & 20 & GPa & Rutquist et al. (2013) \\
Peak cohesion & $c$ & 6.0 & $\mathrm{MPa}$ & Ma and Chen, (2015) \\
Peak friction angle & $\phi$ & 32.23 & degrees & Ma and Chen (2015) \\
Residual cohesion & $c_{\mathrm{r}}$ & 4.39 & $\mathrm{MPa}$ & Ma and Chen (2015) \\
Residual friction angle & $\phi_{\mathrm{r}}$ & 25.17 & degrees & Ma and Chen (2015) \\
Dilation angle & $\psi$ & 10 & degrees & Islam and Skalle (2013) \\
Maximum sorption-induced swelling & $\varepsilon_{\mathrm{L}}^{\mathrm{s}}$ & 0.134 & $\%$ & Chen et al. (2015b) \\
Fracture compressibility & $c_{\mathrm{f}}$ & 0.02 & $1 / \mathrm{MPa}$ & Chen et al. (2015a) \\
Poisson's ratio & $v$ & 0.22 & - & Ma and Chen (2015) \\
Langmuir's isotherm constant & $b_{\mathrm{L}}$ & 0.25 & $1 / \mathrm{MPa}$ & Chen et al. (2015b) \\
In situ horizontal stress & $\sigma_{0}$ & 31.784 & $\mathrm{MPa}$ & Corresponding to 1500 m depth \\
& & & & following Rutqvist et al. \\
Initial reservoir pressure & & & & (2013) \\
wellbore pressure & $p_{0}$ & 24.63 & $\mathrm{MPa}$ & Rutqvist et al. (2013) \\
Wellbore radius & $p_{\mathrm{w}}$ & 5 & $\mathrm{MPa}$ & \\
Biot's coefficient & $R_{\mathrm{w}}$ & 0.216 & $\mathrm{~m}$ & Ma and Chen (2015) \\
Outer radius & $\alpha$ & 1.0 & - & Chen et al. (2015a) \\
\hline & $R_{0}$ & 100.0 & $\mathrm{~m}$ & - \\
\hline
\end{tabular}



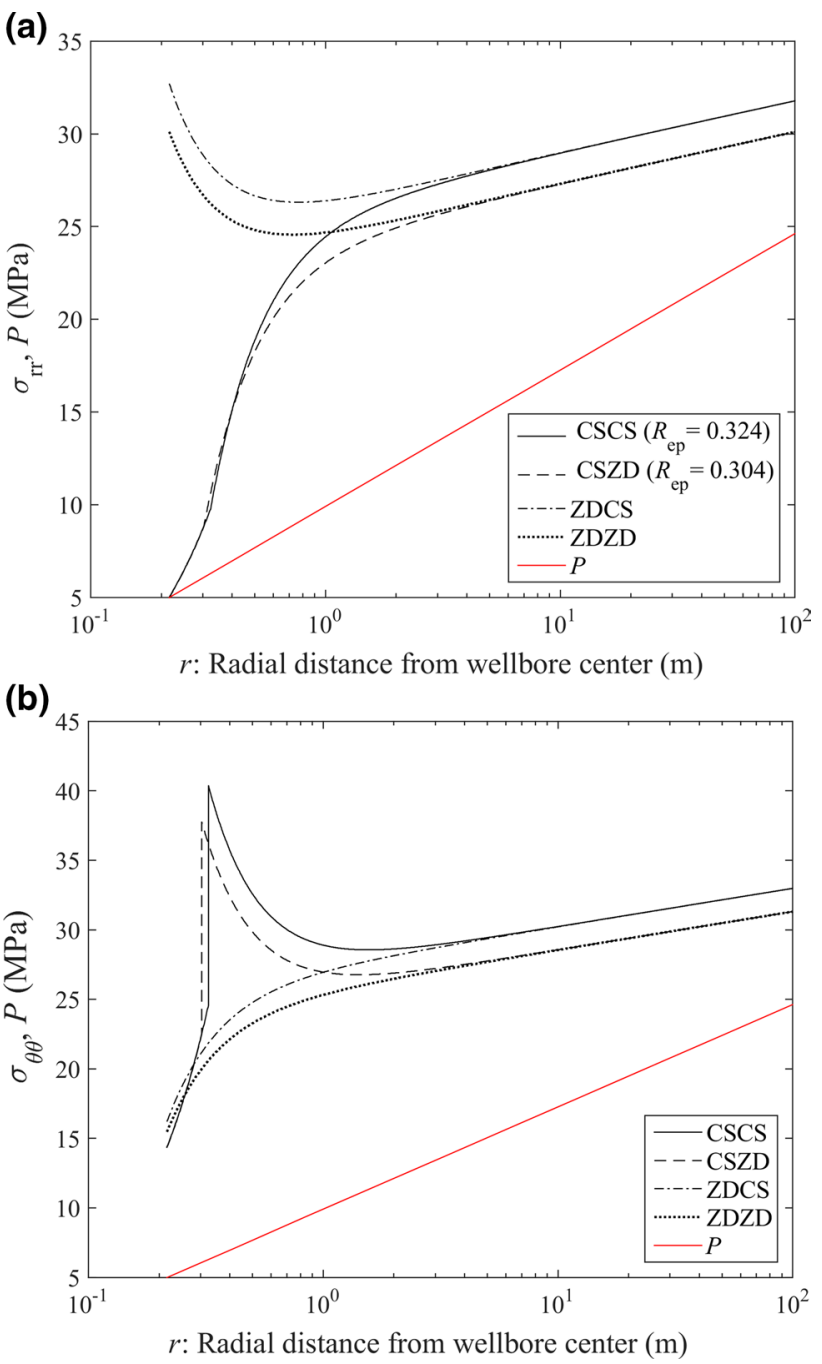

Fig. 3 Profiles of stress within the reservoir: a radial stress, $\mathbf{b}$ tangential stress

failure criterion and a plastic (failure) zone is developed around the wellbore; the maxima in tangential stress profiles coincide with the elastic-plastic interface. Note that the sharp drop of the tangential stress profile at the elastic-plastic interface is due to the brittle failure mechanism of the rock. In other words, whereas the strength of the rock immediately at the elastic-plastic interface is given by peak properties (peak cohesion and friction angle), the strength of the rock within the plastic zone is given by the residual values of cohesion and friction angle. The radius of the plastic zone is larger in the CSCS case $(0.324 \mathrm{~m})$ compared to that in CSZD $(0.304 \mathrm{~m})$ because of lower stress levels in the latter case.

The mean horizontal total and effective stresses, defined as $\sigma_{\mathrm{m}}=\left(\sigma_{r r}+\sigma_{\theta \theta}\right) / 2$ and $\sigma_{\mathrm{m}}^{\prime}=\sigma_{\mathrm{m}}-\alpha p$, respectively (Cui et al. 2007), are depicted in Fig. 4. These definitions are important in the prediction of permeability, which will be (a)

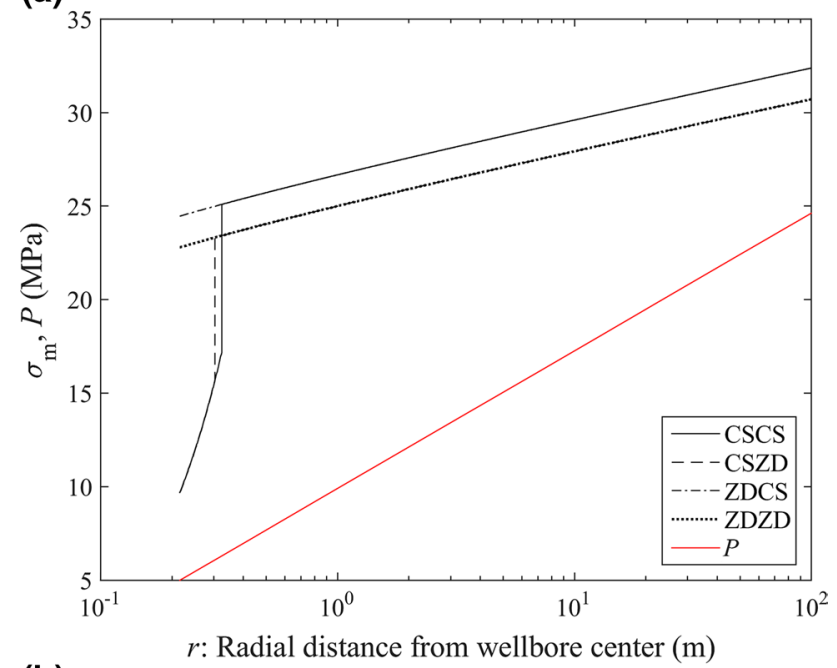

(b)

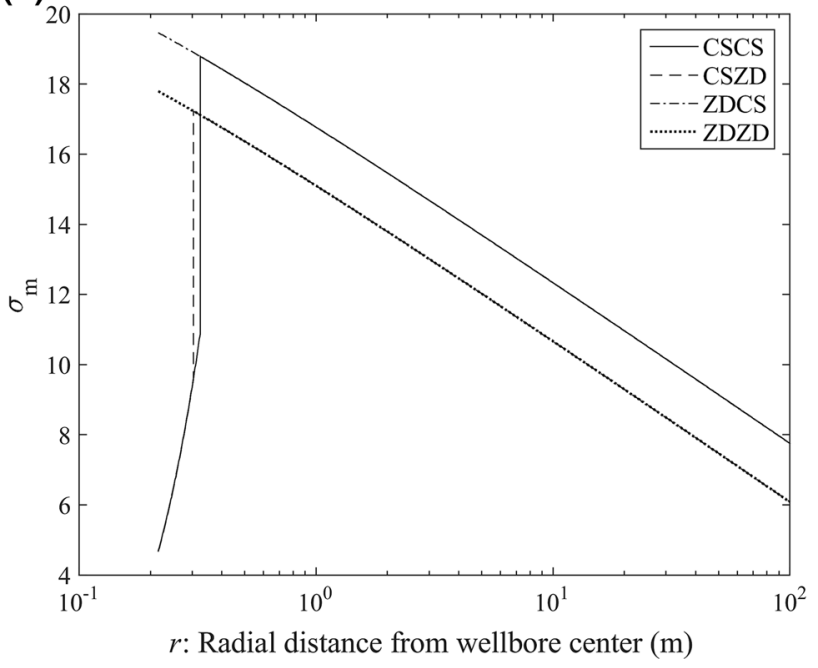

Fig. 4 Distribution of mean horizontal stress for all cases: a total stress, $\mathbf{b}$ effective stress

discussed in detail later. The mean horizontal total stress decreases as it closely follows the reduction of pore pressure from the far-field towards the wellbore (Fig. 4a). In cased-hole analyses (ZDCS and ZDZD), the rock remains fully elastic and therefore the mean horizontal total stress decreases monotonically from the far-field towards the wellbore, with the minimum value occurring at the wellbore wall. For CSCS and CSZD, however, the mean total stress decreases sharply at the elastic-plastic interface, following the trends of radial and tangential stresses shown in Fig. 3. The mean horizontal effective stress is shown in Fig. $4 \mathrm{~b}$, where a maximum can be observed at the interface of the elastic-plastic boundary in CSCS and CSZD cases. It can also be seen that within the elastic zone, the solutions with similar outer boundary conditions show similar trends (CSCS vs. ZDCS and CSZD vs ZDZD), even though their corresponding $\sigma_{r r}$ and $\sigma_{\theta \theta}$ values are different outside the 
elastic zone interface. In other words, for $\sigma_{\mathrm{m}}$ and $\sigma_{\mathrm{m}}^{\prime}$ within the elastic zone, the effect of wellbore boundary condition diminishes and the outer boundary has the dominant effect on the distribution of mean horizontal stress.

Since the main purpose of this study is to understand the effect of plasticity, the profiles of mean horizontal stress for the two open-hole cases need further discussion. These two cases were also modelled using their corresponding fully elastic solutions, as depicted in Fig. 5a, b. Figure 5a shows that the mean horizontal stress estimated using the elastic solutions for CSCS and CSZD are almost identical to those calculated for the cased-hole cases ZDCS and ZDZD (shown in Fig. 4a), respectively, although the distributions of radial and tangential stresses are very different (Fig. 5c, d). This is discussed in more detail in "Appendix 3", but it is mainly because the distribution of radial and tangential stresses in elastic models depends on the condition of the wellbore wall; however, they change in a way that their summation $\left(\sigma_{r r}+\sigma_{\theta \theta}\right)$ remains the same between the cased-hole and open-hole conditions. For example, the radial stress at the wall of the cased hole is much larger than that in the open hole, while the tangential stress decreases due to the lack of any radial displacement. With an open hole, on the other hand, the reduction in radial stress is compensated by the increase in the tangential stress. Thus, following the discussion of Figs. 4 and 5 shows that the effect of brittle-plastic behaviour of rock is only significant within the failure zone near the wellbore.

The estimated permeability is shown in Fig. 6a, which as expected inversely follows the mean horizontal effective stress. For elastoplastic cases, the minima are at the interface of the elastic and plastic zones. This corresponds to the location where the rock is on the verge of failure and therefore can sustain the maximum stress levels; hence, the fractures are at their minimum aperture. On the other hand, in the elastic solutions, the mean effective stress increases monotonically towards the wellbore and therefore the rock near the wellbore is under the maximum compression,
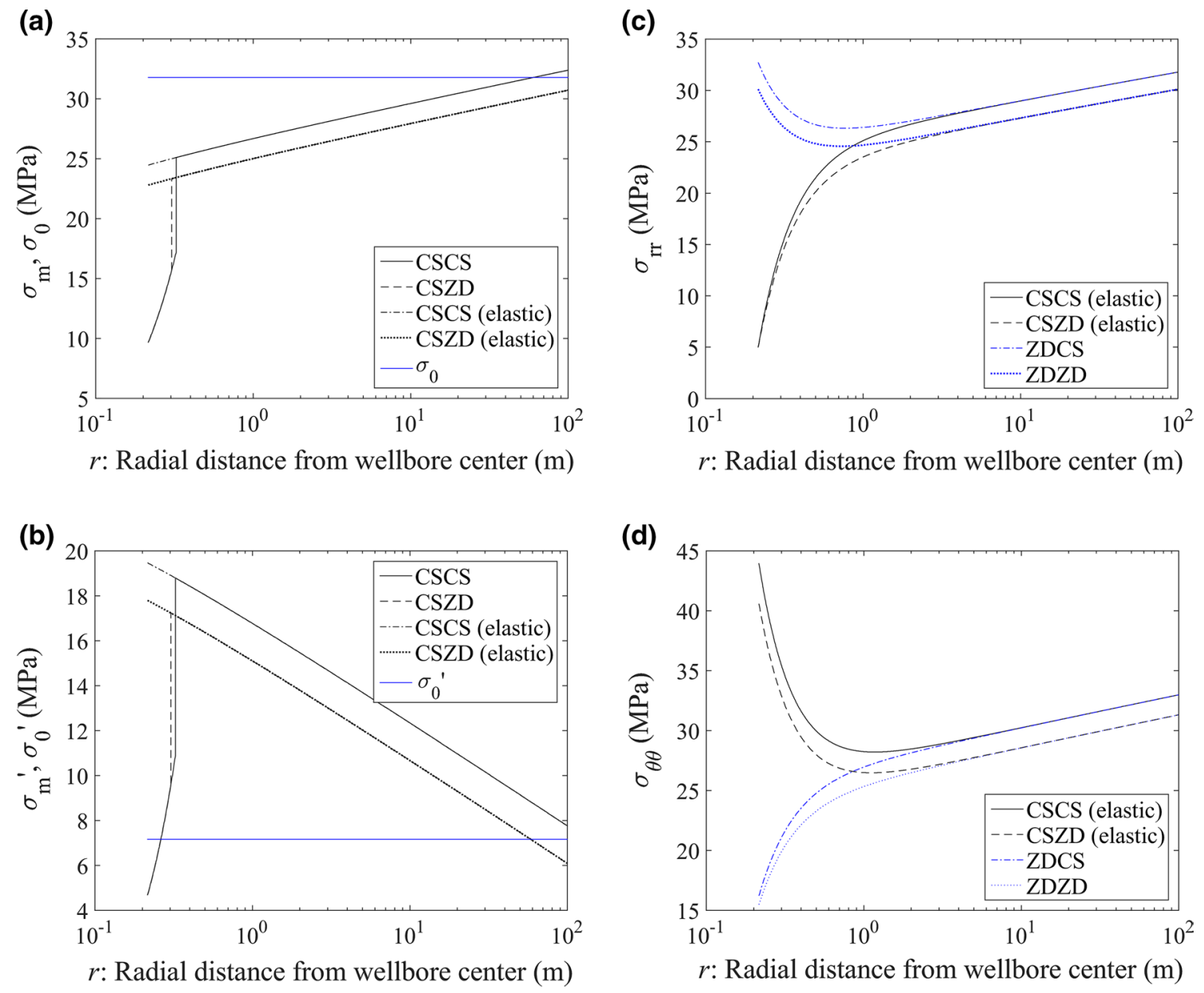

Fig. 5 Comparison of elastic and plastic solutions for open-hole cases (CSCS and CSZD) and the comparison of elastic solutions of openhole cases (CSCS elastic and CSZD elastic) with the cased-hole cases

(ZDCS and ZDZD): a mean total stress, $\mathbf{b}$ effective mean stress, $\mathbf{c}$ radial stress, $\mathbf{d}$ tangential stress 
(a)

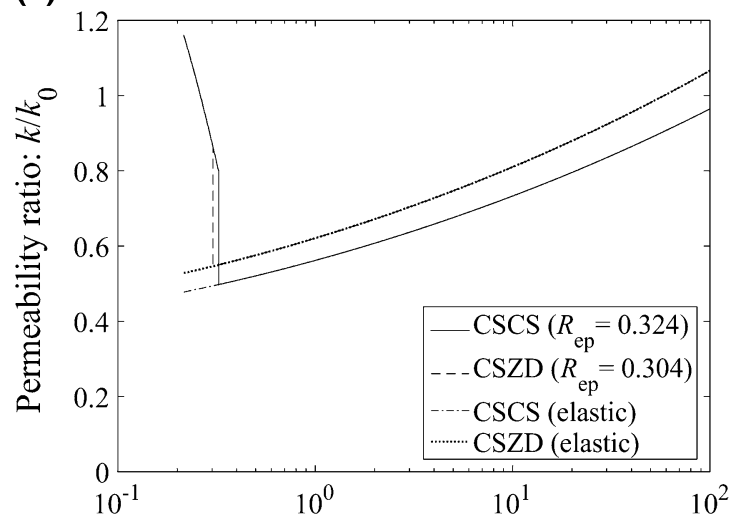

$r$ : Radial distance from wellbore center $(\mathrm{m})$ (b)

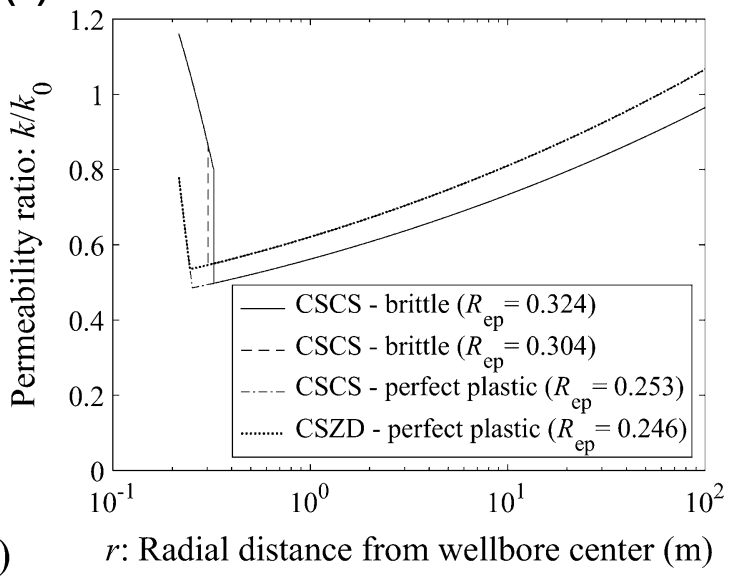

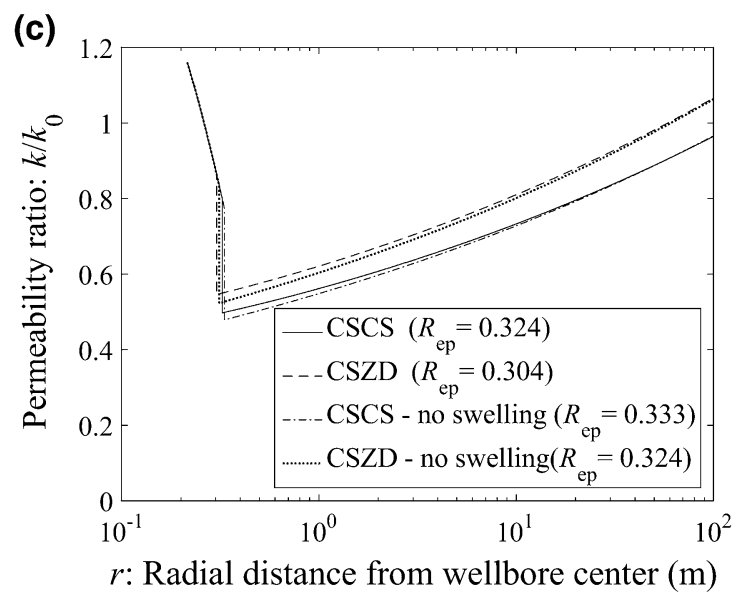

Fig. 6 Permeability of the reservoir with open-hole completion: a comparison between elastic and plastic solutions, b comparison between brittle-plastic and perfectly plastic solutions, $\mathbf{c}$ comparison of the solution with and without swelling effect

which leads to the lowest values of permeability. When the constant radial stress condition is used for the outer boundary (CSCS), the rock mass is pushed towards the wellbore which in turn leads a higher degree of fracture closure and lower permeability compared to the CSZD models (zero displacement at the outer boundary). The effect of brittle failure on rock permeability is shown in Fig. 6b. Compared to perfectly plastic behaviour (with peak strength values), the brittle-plastic behaviour leads to a larger failure zone and lower permeability. This is because, within the plastic zone, the brittle model sustains lower stress levels than the peak strength perfectly plastic model, which leads to reduced permeability in the brittle model.

It should be noted that permeability of fractured rock (and the stress level within the rock mass) depends on the opposing effects of two coupled phenomena: pore pressure change and sorption-induced swelling/shrinkage. First, the reduction of pressure in fractures leads to an increase in the effective stress level, which results in closure of fractures and reduction of permeability. On the other hand, the reduction of pore pressure leads to desorption of gas from the matrix blocks of the rock. Consequently, the matrix blocks shrink and the width of fracture openings increases. Therefore, depending on the poro-mechanical and swelling parameters of the reservoir, the production of gas can lead to either a reduction or an increase in permeability. In the example analysed here, the maximum volumetric strain induced by swelling/shrinkage was chosen to be $0.13 \%$ (an order of magnitude smaller than that of coal). Therefore, the effective stress change induced by pore pressure reduction had a more dominant effect. Figure $6 \mathrm{c}$ shows how the desorptioninduced shrinkage can influence the fracture permeability of a reservoir. The cases including swelling effects resulted in larger permeability throughout the reservoir due to the shrinkage of matrix blocks. Another interesting observation is that the radius of the plastic zone is influenced by the swelling strain despite the fact that it is considered to be an elastic component. This is because the shrinkage of the 
matrix block results in relaxation of stress; therefore, the compressive stress applied to the rock mass reduces and the failed zone radius reduces.

Figure 7 depicts the radius of the plastic zone with respect to change in maximum sorption-induced swelling $\left(\varepsilon_{\mathrm{L}}^{\mathrm{s}}\right)$ and residual strength parameters $\left(c_{\mathrm{r}}, \phi_{\mathrm{r}}\right)$. As sorption-induced volumetric change increases from zero to $1 \%$, the matrix blocks shrink and hence the stress level decreases within the rock mass. As a result, the radius of the plastic zone decreases. No plastic zone developed when using a maximum swelling strain larger than $1.09 \%$ in these examples. In other words, the shrinkage of the matrix can help the mechanical integrity of the wellbore. Increasing the values of residual cohesion and friction angle also leads to a smaller plastic zone; the effect is proportionally greater at lower values of residual strength, i.e. increasing slope of the curves
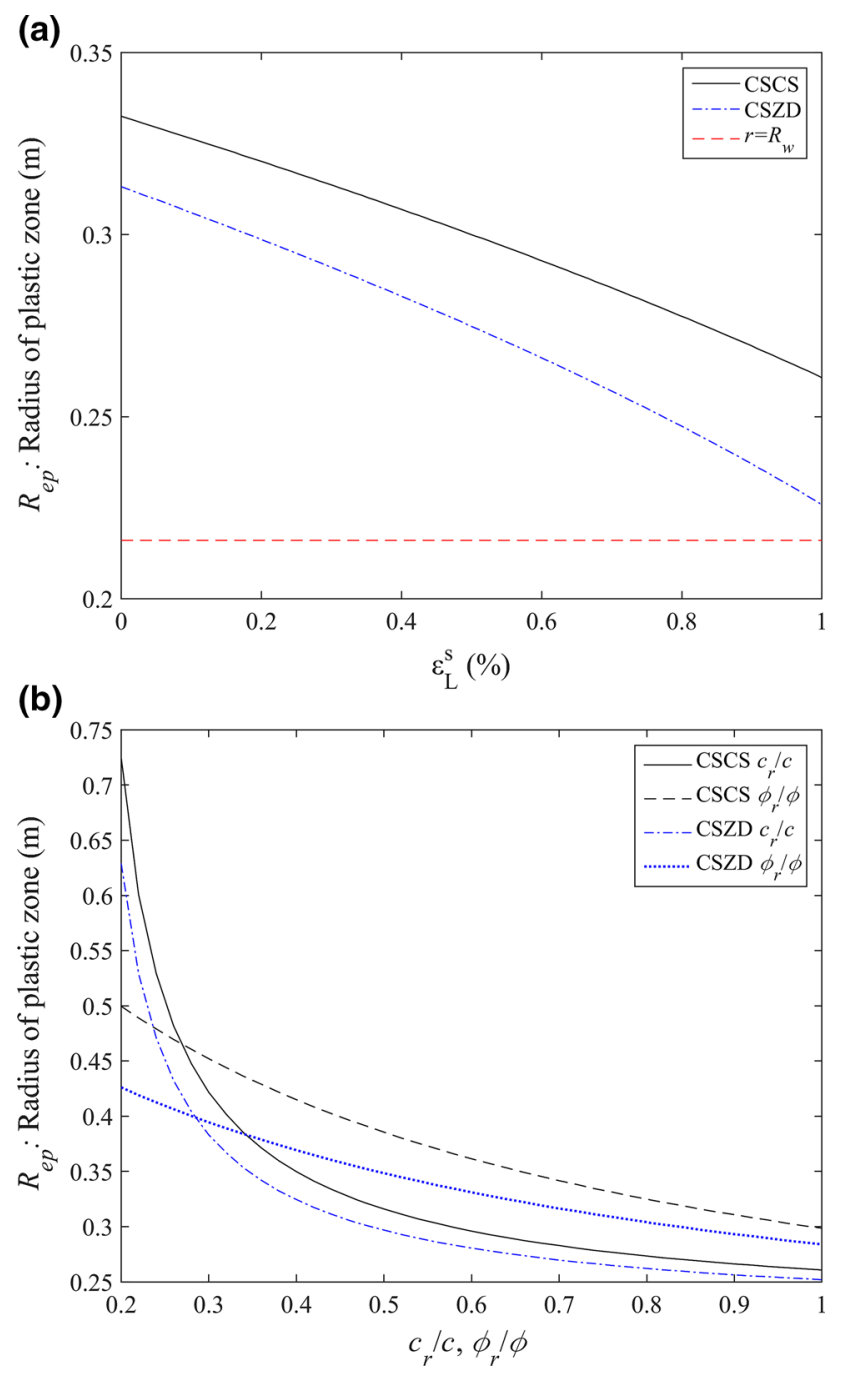

Fig. 7 Radius of the elastic-plastic interface with respect to change in a maximum sorption-induced swelling, $\mathbf{b}$ ratio of residual strength parameters towards lower residual values. This is because a stronger failed rock (higher residual strength) can sustain larger stresses and hence provides better support to the rock mass.

The plastic behaviour of rock has been shown to affect the permeability of a reservoir only in the area very near the wellbore (i.e. within the plastic zone); however, it may have a significant impact on the production flowrate. In order to estimate the effect of near-wellbore permeability on production rate, a simplified approach is adopted in which the equivalent permeability of the whole reservoir is defined by considering parallel ring-shaped layers having different permeability values. In other words, by considering equal radial flowrate in each ring-shaped element of the reservoir, the equivalent permeability can be found. Hence, a dimensionless production flowrate (somewhat similar to productivity index) can be defined, simply as the ratio of production rate of the reservoir with a spatially variable permeability to that of a reservoir with constant initial permeability, which gives

$Q_{\mathrm{D}}=\ln \left(R_{0}-R_{\mathrm{w}}\right) / \int_{R_{\mathrm{w}}}^{R_{0}} \frac{k_{0} \mathrm{~d} r}{r k(r)}$

This parameter can be used to illustrate how changes in permeability influence the rate of gas production from a reservoir. As shown Fig. 8a, an increase in the maximum swelling strain leads to a reduction in the production rate. This is because, although the shrinkage of the shale matrix generally increases the permeability, it restricts the development of the plastic zone (the zone with significantly higher permeability), as demonstrated in Fig. 7, and results in a reduced equivalent permeability of the reservoir. Figure $8 b$ shows how the small plastic zone around the wellbore can significantly affect the production rate. First, note that having a plastic zone developed in elastoplastic solutions with enhanced permeability can lead to higher production rates compared to their elastic counterparts. The production rate also increases with lower residual strength parameters, due to enlargement of the plastic zone around the wellbore, as previously shown in Fig. 7. Such a significant effect of the plastic zone on the equivalent permeability of the whole reservoir and its production rate is due to the fact that the wellbore and its surrounding zone is the bottleneck of the production. This has also been addressed in the context of formation damage where the adverse effect of drilling mud on permeability in the vicinity of the wellbore is studied. Thus, development of a plastic zone with higher permeability around the wellbore can have significant implications on production of gas from shale reservoirs. This highlights the fact that elastic solutions are not able to properly predict reservoir permeability and gas production rates. On the other hand, the use of casings for wellbore stability can significantly reduce the producibility of wells. Obviously, the mechanical 
(a)

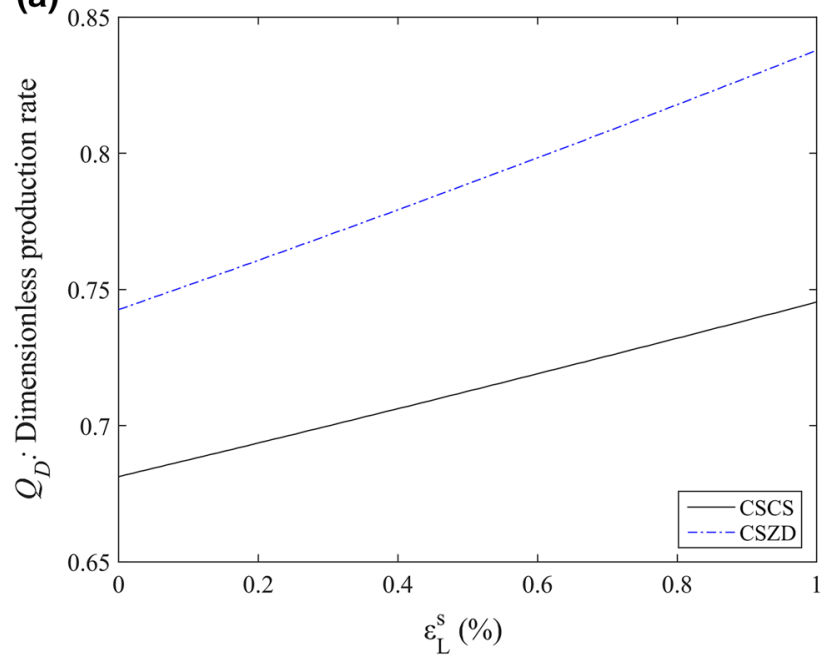

(b)

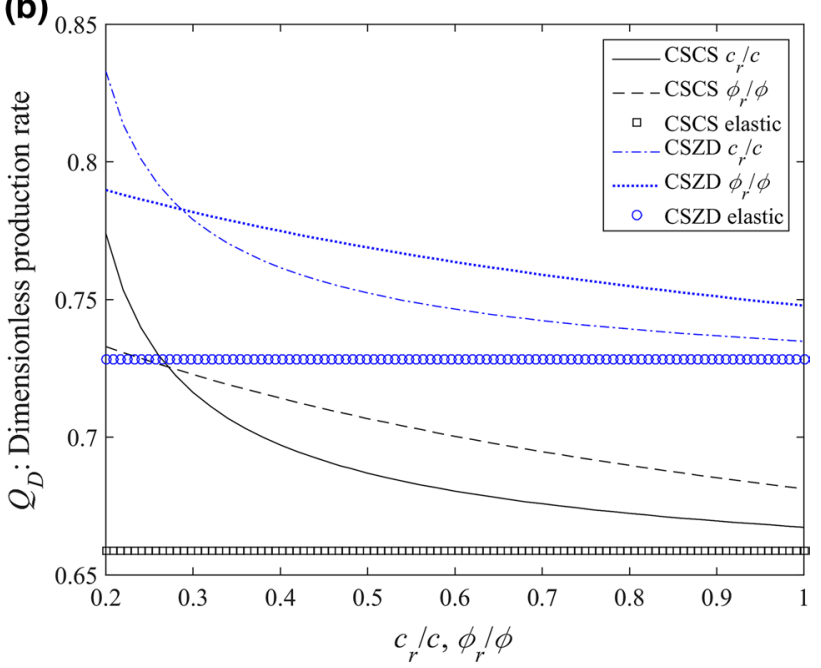

Fig. 8 Dimensionless production rate with respect to change in: a maximum sorption-induced swelling, $\mathbf{b}$ ratio of residual strength parameters

integrity of wellbores is of great importance; however these results suggest that the development of novel wellbore casing solutions (e.g. casings that allow a plastic zone to develop but prevent wellbore caving) could provide significant benefits to the producibility of a wellbore.

\section{Limitations, Verification, and Future Development of the Model}

As a measure of verification of the model, results are compared against experimental and field data in Fig. 9. First, the exponential permeability model used in this study (i.e. Eq. 12) is fitted to experimental datasets available in the literature (usually from triaxial isotropic compression tests). Figure 9a shows that the use of Eq. 12 provides a good estimation of
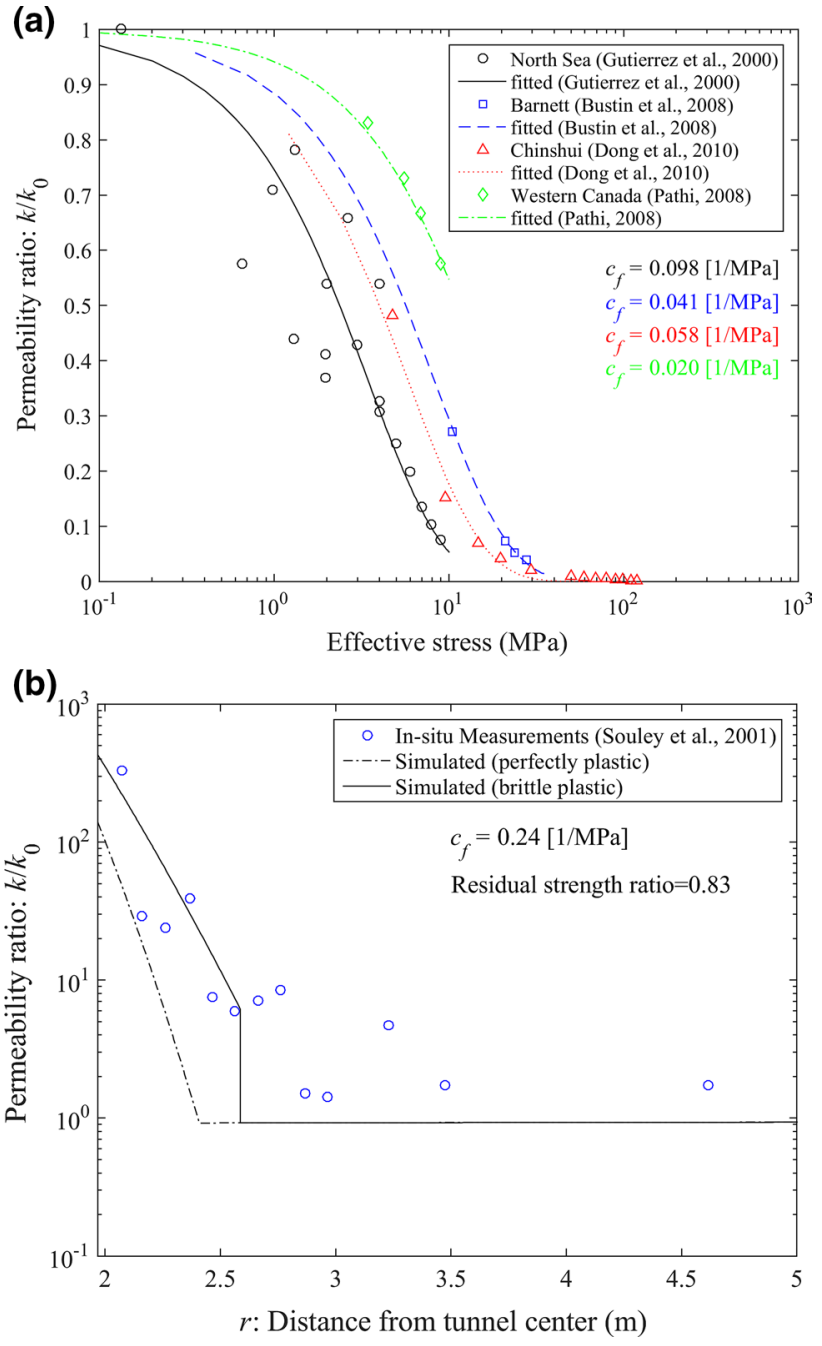

Fig. 9 Assessment of the developed methodology for prediction of permeability: a exponential permeability model for different shales (data from Bustin et al. 2008; Dong et al. 2010; Gutierrez et al. 2000; Pathi 2008), b field data of permeability around a tunnel and model predictions

the permeability for many shales at small scale (core scale), confirming the validity of the exponential relationship for fractured shale reservoirs. Unfortunately, field data presenting the effect of elastoplastic deformations on permeability of shale reservoirs are not available. However, Souley et al. (2001) reported in situ measurements of permeability around a tunnel excavated in granite at Atomic Energy Canada Limited (AECL) Underground Research Laboratory in Canada to address issues related to the disposal of nuclear wastes. There are obviously some important differences between this case and a shale gas reservoir, but these data are still valuable as they provide insight into how plastic deformations can influence permeability around a circular hole. In order to get a good match to in situ measurements, the proposed model was used with no sorption-induced swelling, a fracture compressibility of $0.24 \mathrm{MPa}^{-1}$, and a residual strength ratio of 
0.83 . Note that all other parameters were the same as those in Rutqvist et al. (2009) and Souley et al. (2001), where numerical models were employed to replicate these measurements. It should be noted that the estimated fracture compressibility in this paper is within the range of values reported by Rutqvist et al. (2009). Although this case is simplified here and many processes are neglected, the good agreement between the model and field data provides a verification of the accuracy of the proposed model. It can also be seen that considering the brittle behaviour of the rock is imperative to obtain better predictions of permeability.

Several developments of the model could be considered to address the current limitations. Improvements could be made by developing incremental forms of the solutions such that the stress-strain relations can be implemented within a timedependent reservoir modelling framework (e.g. commercial reservoir simulators). However, care should be taken as the model presented in this paper ignores the fact that severe softening behaviour may lead to localised failure, wherein the assumption of axisymmetric deformation becomes invalid (Lubliner 1990). Studies on the localisation effect on ground reaction curves for circular tunnels (e.g. Alonso et al. 2003; Varas et al. 2005) found that results of radially symmetric solutions were valid from a practical engineering perspective. Thus, similar studies should be undertaken to evaluate the extent to which the solutions developed in this paper are able to represent the actual changes in permeability of shale reservoirs. In addition, unconventional reservoirs such as gas shales are usually stimulated with hydraulic fracturing, which can change the mechanical behaviour of the rock in the vicinity of the wellbore (neglected in this paper), which could be considered for future model developments.

Studies have proposed various models for permeability using different forms of the exponential relationship, but these have mainly concerned with the effect of isotropic effective stress on the permeability of shale and a correction of fracture compressibility (e.g. variation of $c_{\mathrm{r}}$ with effective stress). The permeability model used in this paper assumes that the total sorption strain of the unconfined rock matrix contributes to permeability variation since the sorption strain incorporated in this model was based on measurements made on an unconfined matrix. Zang et al. (2015) introduced the concepts of 'internal swelling' and 'internal swelling ratio' for coal samples to evaluate the effect of sorption-induced swelling on permeability under confined conditions. Such an approach could benefit future developments of permeability models. In addition, recent studies showed that the behaviour of shales can be much more complex, especially when considering shale reservoirs for $\mathrm{CO}_{2}$-EGR. Due to the significance of micro-cracks in shale reservoirs, these findings imply an immediate need for better understanding of the mechanisms of compression-induced fracture initiation and growth in shales. Although studies related to hydraulic fracturing cover this topic to some extent, the relevant micro-scale phenomena are not well understood and cannot be properly predicted, especially for highly anisotropic rocks with sparse organic contents such as shales (Kumar et al. 2016). Such studies can be even more important when considering the $\mathrm{CO}_{2}$ injection for sequestration and production enhancement purposes. The effect of shear displacement on fracture permeability has been discussed in a limited number of studies (Gutierrez et al. 2000; Rutqvist 2015); this is another important topic that requires further investigation.

\section{Conclusions}

In this paper, a series of analytical solutions were presented in a coupled poro-elastoplastic framework, taking into account the sorption-induced swelling/shrinkage of the rock matrix and the brittle failure mechanisms of the rock mass. These solutions were used to model the complex inter-relations between different phenomena during gas production from a gas shale reservoir. The results showed that the rock immediately adjacent to the wellbore may undergo plastic deformations, and depending on the residual strength of the rock, this plastic zone may be enlarged, while the increasing sorption-induced matrix shrinkage leads to smaller plastic zones. The results also showed that the permeability of shale within the plastic zone can increase significantly compared to its initial value, and while the developed plastic zone is generally very small, its implications on producibility of the wellbore can be significant. The advantages and limitations of the developed model were critically discussed. The model was verified using data relating to the permeability of a damaged zone around a tunnel. In the light of this discussion, and considering relevant findings from the literature, a number of directions for future research were proposed to address the lack of understanding on the effect of elastoplastic deformations on permeability of shales. In addition, suggestions were made for further improvement in the models by implementing their incremental forms in an advanced reservoir model and by considering more complex hydro-mechanical boundary conditions. These developments could provide more accurate predictions within the computationally efficient analytical framework presented in the paper.

Open Access This article is distributed under the terms of the Creative Commons Attribution 4.0 International License (http://creativecomm ons.org/licenses/by/4.0/), which permits unrestricted use, distribution, and reproduction in any medium, provided you give appropriate credit to the original author(s) and the source, provide a link to the Creative Commons license, and indicate if changes were made.

\section{Appendix 1: Derivation of Stress and Displacement Solutions}

The derivation of the solution of the elastic zone is presented in the literature (e.g. Masoudian et al. 2016b), and only the solution of the plastic zone is presented here. Substituting the post-failure yield criterion (an equation in the same form as 
Eq. 4 with residual cohesion and friction angle replacing the peak values) and the steady-state pressure distribution (Eq. 8) into the equation of equilibrium (Eq. 2) gives

$\frac{\partial \sigma_{r r}^{\prime}}{\partial r}+\left(1-\gamma_{\mathrm{r}}\right) \frac{\sigma_{r r}^{\prime}}{r}=\frac{Y_{\mathrm{r}}}{r}+\frac{\alpha Q}{r}$

This is a first-order non-homogenous linear differential equation, which can be solved for $\sigma_{r r}^{\prime}$, using the integrating factor method. The value of $\sigma_{\theta \theta}^{\prime}$ can be found by substituting the solution into the post-failure yield criterion. The general solution for $\sigma_{r r}^{\prime}$ can be written as

$\sigma_{r r}^{\prime}=\frac{Y_{\mathrm{r}}}{1-\gamma_{\mathrm{r}}}-\frac{\alpha Q}{1-\gamma_{\mathrm{r}}}+\frac{C_{3}}{r^{1-\gamma_{\mathrm{r}}}}=C_{3} r^{\gamma_{\mathrm{r}}-1}-K$

where $C_{3}$ is the integration constant that can be found using the boundary condition applied to the wellbore wall. For open-hole completions, the bottomhole pressure is equal to the total stress applied to the boundary and hence the effective stress is zero. This gives

$C_{3}=\frac{K}{R_{\mathrm{w}}^{\gamma_{\mathrm{r}}-1}}$

When the wellbore is cased, the displacement at the wellbore wall is assumed to be zero and thus the solution of displacement is needed. The first-order differential equation of displacement in Eq. 6 can be solved to give

$u=u_{\mathrm{ep}}\left(\frac{R_{\mathrm{ep}}}{r}\right)^{\beta}-\frac{1}{r^{\beta}} \int_{r}^{R_{\mathrm{ep}}} \rho^{\beta} g(\rho) \mathrm{d} \rho$

Note that $u_{\text {ep }}$ is the displacement at the elastic-plastic interface and can be found assuming continuity of displacement; its value is equal to that found by the elastic solution at $r=R_{\text {ep }}$. Following the approach suggested by Park and Kim (2006) and employed by Masoudian and Hashemi (2016), $g(r)$ can be found, in the light of the first relationship in Eq. 6, as a function of elastic parts of radial and tangential strain by replacing the solution of stress in the plastic zone into elastic stress-strain relationships. Combining these equations and solving the integral term gives

$$
\begin{aligned}
u= & \frac{(1+v)}{E} r^{-\beta}\left[\frac{E u_{\mathrm{ep}}}{1+v} R_{\mathrm{ep}}^{\beta}-C_{3} A \frac{R_{\mathrm{ep}}^{\beta+\gamma_{\mathrm{r}}}-r^{\beta+\gamma_{\mathrm{r}}}}{\beta+\gamma_{\mathrm{r}}}\right. \\
& \left.-\left(B Y_{\mathrm{r}}-A K\right) \frac{R_{\mathrm{ep}}^{\beta+1}-r^{\beta+1}}{\beta+1}+\frac{1+\beta}{3} E\left(F_{\varepsilon, \beta}\left(R_{\mathrm{ep}}\right)-F_{\varepsilon, \beta}(r)\right)\right]
\end{aligned}
$$

Therefore, for a cased-hole completion, $C_{3}$ can be found by solving this equation for $u=0$. It is evident from these equations that the solution needs the elastic-plastic interface ( $R_{\text {ep }}$ ) to be known. In order to find $R_{\text {ep }}$, the continuity of radial stress will be postulated, which means that both elastic and plastic solutions must be equal at $r=R_{\text {ep }}$. In other words, the elastic solution needs to satisfy the peak yield criterion (Eq. 4), because the rock at $r=R_{\text {ep }}$ is at its peak strength. Therefore, substituting Eq. 13 into Eq. 4 gives a solution for stresses $r=R_{\text {ep }}$

$$
\begin{aligned}
\left.\sigma_{r r}\right|_{r=R_{\mathrm{ep}}}= & \frac{1}{1+\gamma}\left[2 C_{1}+\left.\left(\gamma-\frac{v}{1-v}\right) \alpha P\right|_{r=R_{\mathrm{ep}}}\right. \\
& \left.+\left.\frac{E}{3(1-v)} \varepsilon_{v}^{\mathrm{e}, \mathrm{s}}\right|_{r=R_{\mathrm{ep}}}-Y\right]
\end{aligned}
$$

The effective radial stress at the elastic-plastic interface can also be found from Eq. 23 and, by including the pore pressure effect, the total radial stress can be written as

$\left.\sigma_{r r}\right|_{r=R_{\mathrm{ep}}}=\frac{Y_{\mathrm{r}}}{1-\gamma_{\mathrm{r}}}-\frac{\alpha Q}{1-\gamma_{\mathrm{r}}}+C_{3} R_{\mathrm{ep}}^{\gamma_{\mathrm{r}}-1}+\left.\alpha P\right|_{r=R_{\mathrm{ep}}}$

The total stress at $r=R_{\text {ep }}$ must be unique (i.e. radial stress continuity) and therefore an equality can be written as

$$
\begin{gathered}
\frac{1}{1+\gamma}\left[2 C_{1}+\left.\left(\gamma-\frac{v}{1-v}\right) \alpha P\right|_{r=R_{\text {ep }}}+\left.\frac{E}{3(1-v)} \varepsilon_{v}^{\mathrm{e}, \mathrm{s}}\right|_{r=R_{\mathrm{ep}}}-Y\right] \\
=\frac{Y_{\mathrm{r}}}{1-\gamma_{\mathrm{r}}}-\frac{\alpha Q}{1-\gamma_{\mathrm{r}}}+C_{3} R_{\mathrm{ep}}^{\gamma_{\mathrm{e}}-1}+\left.\alpha P\right|_{r=R_{\mathrm{ep}}}
\end{gathered}
$$

Ideally, this equality is solved analytically to give a closedform expression of $R_{\text {ep }}$, but this can be difficult, if not impossible. Thus, a trial-and-error scheme can be used to find the root. The root of $R_{\mathrm{ep}}$ is then admissible only if it is within the model
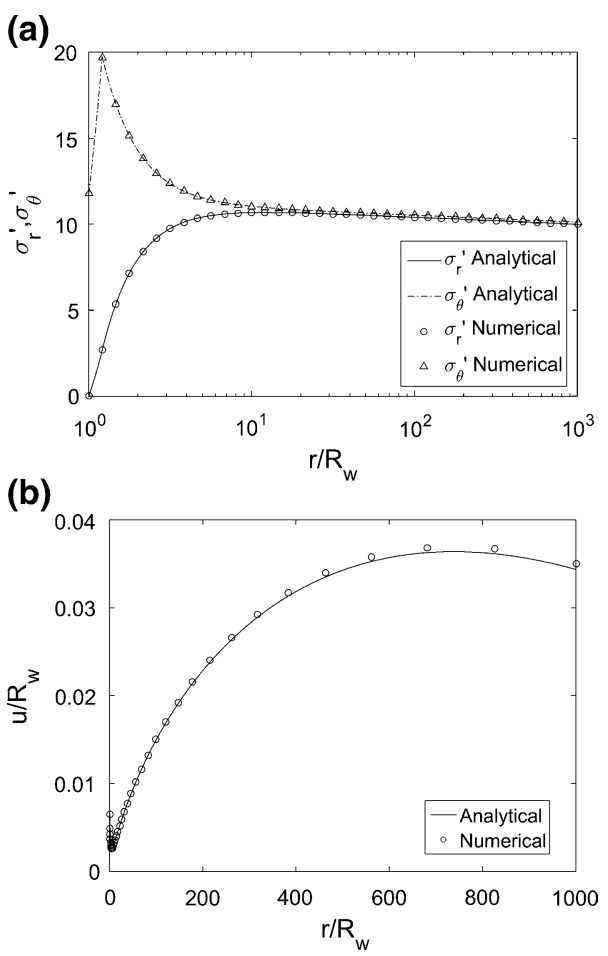

Fig. 10 Verification of CSCS case for: a stress solution, b displacement solution 
domain $\left[R_{\mathrm{w}}, R_{0}\right]$; i.e. if no root is found or it is smaller than the wellbore radius or larger than the reservoir radius, the reservoir remains elastic and no failure zone is developed around the wellbore. It should also be noted that the analytical solutions of stress and displacement were compared to numerical solutions to verify their performance with perfectly plastic behaviour. Such a verification for the CSCS case is depicted in Fig. 10.

\section{Appendix 2: Integration Constants for Elastic Cases}

See Table 3.

\section{Appendix 3: Comparative Analysis of $\sigma_{\mathrm{m}}$ for Different Cases}

It is useful to note how different boundary conditions on the wellbore affect the value of $\sigma_{\mathrm{m}}$ within the elastic zone. As shown in the paper, CSCS and CSZD cases result in very similar profiles for $\sigma_{\mathrm{m}}$ in the elastic zone as ZDCS and ZDZD, respectively. To better explain and justify this, a comparison of all the terms involved in $\sigma_{\mathrm{m}}$ can be carried out. $\sigma_{\mathrm{m}}$ is defined as the mean of radial and tangential stress as follows:

$\sigma_{\mathrm{m}}=\frac{\sigma_{r r}+\sigma_{\theta \theta}}{2}=C_{1}+\frac{f(r)}{2}$
Table 3 Integration constants for different sets of boundary conditions in elastic cases

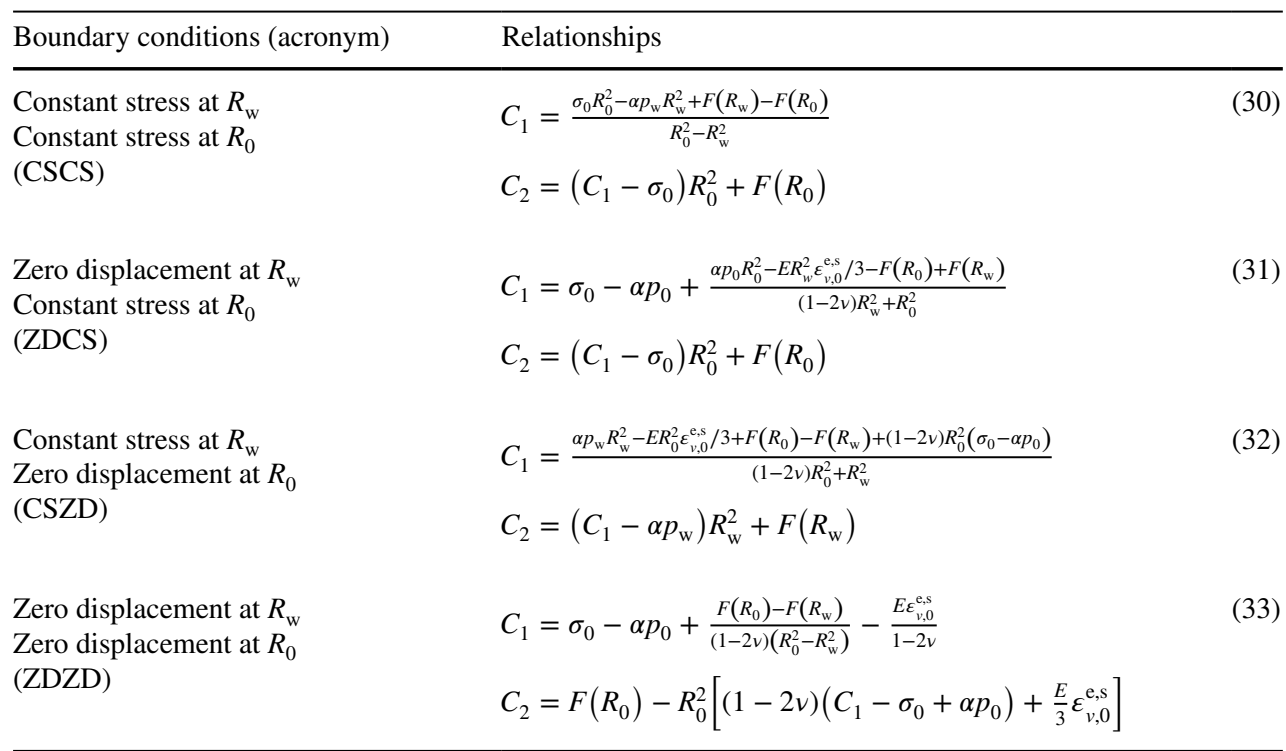

Table 4 Integration constants in solution of mean horizontal stress within the elastic zone

\begin{tabular}{|c|c|}
\hline Boundary conditions (acronym) & Relationships \\
\hline CSCS and ZDCS & $C_{1}=\frac{\xi\left[Y-f\left(R_{\mathrm{ep}}\right)-(\gamma-1) \alpha P\left(R_{\mathrm{ep}}\right)\right]+(\gamma+1)\left[\frac{F\left(R_{\mathrm{ep}}\right)-F\left(R_{0}\right)}{R_{0}^{2}}+\sigma_{0}\right]}{(\gamma+1)-\xi(\gamma-1)} \cong \sigma_{0}-\frac{F\left(R_{0}\right)}{R_{0}^{2}}$ \\
\hline CSCS elastic & $C_{1}=\frac{\sigma_{0}-\alpha p_{\mathrm{w}} \xi+\frac{F\left(R_{\mathrm{w}}\right)-F\left(R_{0}\right)}{R_{0}^{2}}}{1-\xi} \cong \sigma_{0}-\frac{F\left(R_{0}\right)}{R_{0}^{2}}$ \\
\hline ZDCS elastic & $C_{1}=\sigma_{0}-\alpha p_{0}+\frac{\alpha p_{0}-E \xi \varepsilon_{v, 0}^{\mathrm{e}, \mathrm{s}} / 3-\frac{F\left(R_{0}\right)-F\left(R_{\mathrm{w}}\right)}{R_{0}^{2}}}{(1-2 v) \xi+1} \cong \sigma_{0}-\frac{F\left(R_{0}\right)}{R_{0}^{2}}$ \\
\hline CSZD and ZDZD & $\begin{array}{l}C_{1}=\frac{1}{\xi(1-\gamma)-(1+\gamma)(1-2 v)}\left\{\xi\left[Y-f\left(R_{\mathrm{ep}}\right)-(\gamma-1) \alpha P\left(R_{\mathrm{ep}}\right)\right]+(\gamma+1)\right. \\
\left.\quad\left(\frac{F\left(R_{\mathrm{ep}}\right)-F\left(R_{0}\right)}{R_{0}^{2}}+\left[\frac{E}{3} \varepsilon_{v, 0}^{\mathrm{e}, \mathrm{s}}-(1-2 v)\left(\sigma_{0}-\alpha p_{0}\right)\right]\right)\right\} \cong \sigma_{0}-\alpha p_{0}+\frac{1}{1-2 \nu}\left(\frac{F\left(R_{0}\right)}{R_{0}^{2}}-\frac{E}{3} \varepsilon_{v, 0}^{\mathrm{e}, \mathrm{s}}\right)\end{array}$ \\
\hline CSZD elastic & $C_{1}=\frac{\alpha p_{\mathrm{w}} \xi-E \varepsilon_{v, 0}^{\mathrm{e}, \mathrm{s}} / 3+\frac{F\left(R_{0}\right)-F\left(R_{\mathrm{w}}\right)}{R_{0}^{2}}+(1-2 v)\left(\sigma_{0}-\alpha p_{0}\right)}{(1-2 v)+\xi} \cong \sigma_{0}-\alpha p_{0}+\frac{1}{1-2 v}\left(\frac{F\left(R_{0}\right)}{R_{0}^{2}}-\frac{E}{3} \varepsilon_{v, 0}^{\mathrm{e}, \mathrm{s}}\right)$ \\
\hline ZDZD elastic & $C_{1}=\sigma_{0}-\alpha p_{0}+\frac{F\left(R_{0}\right)-F\left(R_{\mathrm{w}}\right)}{(1-2 v) R_{0}^{2}(1-\xi)}-\frac{E \varepsilon_{v, 0}^{\mathrm{e}, \mathrm{s}}}{1-2 v} \cong \sigma_{0}-\alpha p_{0}+\frac{1}{1-2 v}\left(\frac{F\left(R_{0}\right)}{R_{0}^{2}}-\frac{E}{3} \varepsilon_{v, 0}^{\mathrm{e}, \mathrm{s}}\right)$ \\
\hline
\end{tabular}


Since $f(r)$ is the same for all boundary conditions, the differences must relate to $C_{1}$. On the other hand, the plastic zone is always located very close to the wellbore. Thus, both $R_{\mathrm{w}}$ and $R_{\mathrm{ep}}$ can be considered very small compared to $R_{0}$. Consequently, a ratio given by $\xi=R_{\mathrm{w}}^{2} / R_{0}^{2} \approx R_{\mathrm{ep}}^{2} / R_{0}^{2} \approx 10^{-6}$ can be implemented in all equations for $C_{1}$ and neglected. Furthermore, $F\left(R_{\mathrm{ep}}\right) \ll F\left(R_{0}\right)$ and can also be neglected. Considering these aspects for all four boundary condition cases results in the integration constants presented in Table 4.

\section{References}

Hull KL, Abousleiman, YN, Han Y, Al-Muntasheri GA, Hosemann P, Parker SS, Howard CB (2015) New insights on the mechanical characterization of Kerogen-rich shale, KRS. In: Abu Dhabi international petroleum exhibition and conference. Society of Petroleum Engineers, Abu Dhabi, UAE, p 25. http://dx.doi.org/10.2118 /177628-MS

Alexander T, Baihly J, Boyer C, Clark B, Waters G, Jochen V, Le Calvez J, Lewis R, Miller CK, Thaeler J, Toelle BE (2011) Shale gas revolution. Oilfield Rev 23(3):40-57

Alonso E, Alejano LR, Varas F, Fdez-Manin G, Carranza-Torres C (2003) Ground response curves for rock masses exhibiting strain-softening behaviour. Int J Numer Anal Meth Geomech 27(13):1153-1185. https://doi.org/10.1002/nag.315

Amann F, Button EA, Evans KF, Gischig VS, Blümel M (2011) Experimental study of the brittle behavior of clay shale in rapid unconfined compression. Rock Mech Rock Eng 44(4):415-430. https:// doi.org/10.1007/s00603-011-0156-3

Amann-Hildenbrand A, Ghanizadeh A, Krooss BM (2012) Transport properties of unconventional gas systems. Mar Petrol Geol 31(1):90-99. https://doi.org/10.1016/j.marpetgeo.2011.11.009

Bustin RM, Bustin AMM, Cui A, Ross D, Pathi VM (2008) Impact of shale properties on pore structure and storage characteristics. Soc Petrol Eng. https://doi.org/10.2118/119892-MS

Carey JW, Lei Z, Rougier E, Mori H, Viswanathan H (2015) Fract-permeability behavior of shale. J Unconv Oil Gas Resour 11:27-43. https://doi.org/10.1016/j.juogr.2015.04.003

Carroll SA, McNab WW, Torres SC (2011) Experimental study of cement-sandstone/shale-brine- $\mathrm{CO}_{2}$ interactions. Geochem Trans 12(1):9. https://doi.org/10.1186/1467-4866-12-9

Chen D, Pan Z, Ye Z (2015a) Dependence of gas shale fracture permeability on effective stress and reservoir pressure: model match and insights. Fuel 139:383-392. https://doi.org/10.1016/j.fuel.2014. 09.018

Chen T, Feng X-T, Pan Z (2015b) Experimental study of swelling of organic rich shale in methane. Int J Coal Geol 150-151:64-73. https://doi.org/10.1016/j.coal.2015.08.001

Cho Y, Ozkan E, Apaydin OG (2013) Pressure-dependent naturalfracture permeability in shale and its effect on shale-gas well production. SPE Reserv Eval Eng 16(2):216-228. https://doi. org/10.2118/159801-PA

Cui X, Bustin RM, Chikatamarla L (2007) Adsorption-induced coal swelling and stress: Implications for methane production and acid gas sequestration into coal seams. J Geophys Res Solid Earth 112:B10. https://doi.org/10.1029/2004jb003482

Curtis JB (2002) Fractured shale-gas systems. AAPG Bull 86(11):1921-1938. https://doi.org/10.1306/61EEDDBE-173E -11D7-8645000102C1865D
Dong J-J, Hsu J-Y, Wu W-J, Shimamoto T, Hung J-H, Yeh E-C, Wu Y-H, Sone H (2010) Stress-dependence of the permeability and porosity of sandstone and shale from TCDP Hole-A. Int J Rock Mech Min Sci 47(7):1141-1157. https://doi.org/10.1016/j.ijrm ms.2010.06.019

Gale JFW, Laubach SE, Olson JE, Eichhubl P, Fall A (2014) Natural fractures in shale: a review and new observations. AAPG Bull 98(11):2165-2216. https://doi.org/10.1306/08121413151

Gensterblum Y, Ghanizadeh A, Cuss RJ, Amann-Hildenbrand A, Krooss BM, Clarkson CR, Harrington JF, Zoback MD (2015) Gas transport and storage capacity in shale gas reservoirs-a review. Part A: transport processes. J Unconv Oil Gas Resour 12:87-122. https://doi.org/10.1016/j.juogr.2015.08.001

Gutierrez M, Øino LE, Nygård R (2000) Stress-dependent permeability of a de-mineralised fracture in shale. Mar Petrol Geol 17(8):895907. https://doi.org/10.1016/S0264-8172(00)00027-1

Han G, Dusseault MB (2003) Description of fluid flow around a wellbore with stress-dependent porosity and permeability. J Petrol Sci Eng 40(1-2):1-16. https://doi.org/10.1016/S0920-4105(03)0004 7-0

Hill DG, Nelson CR (2000) Gas productive fractured shales: an overview and update. Gas TIPS 6(2):4-13

Huang X, Bandilla KW, Celia MA (2016) Multi-physics pore-network modeling of two-phase shale matrix flows. Transp Porous Media 111(1):123-141. https://doi.org/10.1007/s11242-015-0584-8

Islam MA, Skalle P (2013) Experimentally evaluating shale dilation behavior. In: Chatellier J-Y, Jarvie DM (eds) Critical assessment of shale resource plays. American Association of Petroleum Geologists, Tulsa, p 205

Kumar H, Elsworth D, Mathews JP, Marone C (2016) Permeability evolution in sorbing media: analogies between organic-rich shale and coal. Geofluids 16(1):43-55. https://doi.org/10.1111 /gfl.12135

Li M, Yin G, Xu J, Cao J, Song Z (2016) Permeability evolution of shale under anisotropic true triaxial stress conditions. Int J Coal Geol 165:142-148. https://doi.org/10.1016/j.coal.2016.08.017

Liang C, Chen M, Jin Y, Lu Y (2014) Wellbore stability model for shale gas reservoir considering the coupling of multi-weakness planes and porous flow. J Nat Gas Sci Eng 21:364-378. https:// doi.org/10.1016/j.jngse.2014.08.025

Lubliner J (1990) Plasticity theory. Macmillan, New York, p 50. ISBN 0486462900

Lyu Q, Ranjith PG, Long X, Kang Y, Huang M (2015) A review of shale swelling by water adsorption. J Nat Gas Sci Eng Part 27(3):1421-1431. https://doi.org/10.1016/j.jngse.2015.10.004

Ma T, Chen P (2015) A wellbore stability analysis model with chemical-mechanical coupling for shale gas reservoirs. J Nat Gas Sci Eng 26:72-98. https://doi.org/10.1016/j.jngse.2015.05.028

Masoudian MS, Hashemi MA (2016) Analytical solution of a circular opening in an axisymmetric elastic-brittle-plastic swelling rock. J Nat Gas Sci Eng Part A 35:483-496. https://doi. org/10.1016/j.jngse.2016.08.076

Masoudian MS, Airey DW, El-Zein A (2016a) The role of coal seam properties on coupled processes during $\mathrm{CO}_{2}$ sequestration: a parametric study. Greenh Gases Sci Technol (in Press). http:// dx.doi.org/10.1002/ghg. 1575

Masoudian MS, El-Zein A, Airey DW (2016b) Modelling stress and strain in coal seams during $\mathrm{CO}_{2}$ injection incorporating the rock-fluid interactions. Comput Geotech 76:51-60. https://doi. org/10.1016/j.compgeo.2016.02.010

McGlade C, Speirs J, Sorrell S (2013) Unconventional gas-a review of regional and global resource estimates. Energy 55:571-584. https://doi.org/10.1016/j.energy.2013.01.048

Mehmani A, Prodanović M, Javadpour F (2013) Multiscale, multiphysics network modeling of shale matrix gas flows. Transp 
Porous Media 99(2):377-390. https://doi.org/10.1007/s112 42-013-0191-5

Palmer I (2009) Permeability changes in coal: analytical modeling. Int J Coal Geol 77(1-2):119-126. https://doi.org/10.1016/j.coal 2008.09.006

Pan Z, Connell LD (2012) Modelling permeability for coal reservoirs: a review of analytical models and testing data. Int $\mathbf{J}$ Coal Geol 92:1-44. https://doi.org/10.1016/j.coal.2011.12.009

Park K-H, Kim Y-J (2006) Analytical solution for a circular opening in an elastic-brittle-plastic rock. Int J Rock Mech Min Sci 43(4):616-622. https://doi.org/10.1016/j.ijrmms.2005.11.004

Pathi VSM (2008) Factors affecting the permeability of gas shales. PhD Thesis, The University of British Columbia, Vancouver, Canada

Rutqvist J (2015) Fractured rock stress-permeability relationships from in situ data and effects of temperature and chemical-mechanical couplings. Geofluids 15(1-2):48-66. https://doi.org/10.1111/ gfl.12089

Rutqvist J, Börgesson L, Chijimatsu M, Hernelind J, Jing L, Kobayashi A, Nguyen S (2009) Modeling of damage, permeability changes and pressure responses during excavation of the TSX tunnel in granitic rock at URL, Canada. Environ Geol 57(6):1263-1274. https://doi.org/10.1007/s00254-008-1515-6

Rutqvist J, Rinaldi AP, Cappa F, Moridis GJ (2013) Modeling of fault reactivation and induced seismicity during hydraulic fracturing of shale-gas reservoirs. J Petrol Sci Eng 107:31-44. https://doi. org/10.1016/j.petrol.2013.04.023

Shi JQ, Durucan S (2005) A model for changes in coalbed permeability during primary and enhanced methane recovery. SPE Reserv Eval Eng. https://doi.org/10.2118/87230-PA

Soeder DJ (1988) Porosity and permeability of Eastern Devonian gas shale. SPE Form Eval 3(1):116-124. https://doi.org/10.2118/1521 3-PA

Sone H, Zoback MD (2013) Mechanical properties of shale-gas reservoir rocks - part 2: ductile creep, brittle strength, and their relation to the elastic modulus. Geophysics 78(5):D393-D402. https://doi. org/10.1190/geo2013-0051.1
Song F, Warpinski N, Toksöz M (2014) Full-waveform based microseismic source mechanism studies in the Barnett Shale: linking microseismicity to reservoir geomechanics. Geophysics 79(2):KS13-KS30. https://doi.org/10.1190/geo2013-0094.1

Souley M, Homand F, Pepa S, Hoxha D (2001) Damage-induced permeability changes in granite: a case example at the URL in Canada. Int J Rock Mech Min Sci 38(2):297-310. https://doi. org/10.1016/S1365-1609(01)00002-8

Spencer CW (1989) Review of characteristics of low-permeability gas reservoirs in Western United States. AAPG Bull 73(5):613-629

Varas F, Alonso E, Alejano LR, Manín GF (2005) Study of bifurcation in the problem of unloading a circular excavation in a strainsoftening material. Tunn Undergr Space Technol 20(4):311-322. https://doi.org/10.1016/j.tust.2004.12.003

Wang FP, Reed RM (2009) Pore networks and fluid flow in gas shales. In: SPE annual technical conference and exhibition. Society of Petroleum Engineers, New Orleans, p 3. http://dx.doi.org/10.2118 /124253-MS

Yuan W, Pan Z, Li X, Yang Y, Zhao C, Connell LD, Li S, He J (2014) Experimental study and modelling of methane adsorption and diffusion in shale. Fuel Part A 117:509-519. https://doi.org/10.1016 /j.fuel.2013.09.046

Zang J, Wang K, Zhao Y (2015) Evaluation of gas sorption-induced internal swelling in coal. Fuel 143(Supplement C):165-172. http s://doi.org/10.1016/j.fuel.2014.11.007

Zhou T, Zhang S, Feng Y, Shuai Y, Zou Y, Li N (2016) Experimental study of permeability characteristics for the cemented natural fractures of the shale gas formation. J Nat Gas Sci Eng 29:345-354. https://doi.org/10.1016/j.jngse.2016.01.005 